\title{
Lucha armada, militancia y dictadura. Ficciones de mercado en la literatura argentina
}

GABRIELA ALEJANDRA GALEANO Universidad Autónoma de Entre Ríos, Argentina / gabrialgaleano@hotmail.com

\begin{abstract}
Resumen
La novelística argentina de las últimas tres décadas no sólo ha interrogado, casi en forma obsesiva, la experiencia dictatorial sino que este gesto ha sido recurrentemente laureado por organismos nacionales e internacionales de legitimación literaria. Las distintas instancias de coronación han premiado en forma constante y regular novelas sobre la lucha armada, la militancia y la dictadura, especialmente organizadas en torno al cronotopo de pruebas y aventuras, siendo su variante genérica policial y los que plantean la imposibilidad de un tiempo ideal, los más valorados. Estas ficcionalizaciones consagradas concentraron significaciones alrededor de la violencia en un nuevo regimen de memoria (Lvovich y Bisquert:10).
\end{abstract}

Palabras clave: novelística / posdictadura / premios literarios / cronotopo

\section{Armed struggle, militancy and dictatorship. Fiction's market in argentine literature \\ Abstract}

This investigation analyzes the relation between the Argentina novel award's mecahnisms during last three decades, when for the transnationalization's edition heat, acquiered a strong legitimizing power of novels and author's projects and the coronation of novels about the last dictatorship.The different instances of coronation, have laureate regularly and constantly novels about the seventies armed struggled, military and dictatorship, specially organized around adventure's chronotope. It ist its police variant and wich they raise the impossibility of an ideal time, are the most valued, and this fictioinalization meanings concentrated around violence in a new memory's regime.

Key words: transnationalization's edition / litteray award's / novel / dictatorship / chronotope

Fecha de recepción: 24/2/2017; envío con modificaciones: 6/12/2017; fecha de aceptación: 16/12/2017

Para citar este artículo: Galeano, Gabriela Alejandra (2018). «Lucha armada, militancia y dictadura. Ficciones de mercado en la literatura argentina». El taco en la brea 7 (diciembre-mayo), 34-62 Santa Fe, Argentina: UNL. DOI: https://doi.org/10.14409/tb.voi7.7353 


\section{Novelas sobre la dictadura y premios literarios}

\section{a) Corpus y periodización}

Poner en relación la serie de novelas sobre la militancia, lucha armada y dictadura con los mecanismos de premiación implicó en primer lugar el establecimiento de un corpus y su periodización. Así, a partir de un registro, no exhaustivo, de autores, títulos, editoriales y premios se pudo comprobar que sobre un total de 178 novelas publicadas a lo largo de 31 años, 71 fueron distinguidas por diferentes instancias de consagración privada, de pares o pública, nacionales e internacionales. En la selección de este espectro de textos que conformaron el corpus sobre el que se sentó el análisis, se tuvo en cuenta no sólo las novelas que alcanzaron el primer premio, sino también los segundos, o menciones y selecciones especiales porque en estas sanciones no sólo se pone de manifiesto una adjudicación de valor sino que gravitan en la esfera editorial al momento de decidir una publicación.

Ahora bien, para una mejor organización del trabajo, el corpus se periodizó en tres décadas, teniendo en cuenta la estructuración temporal propuesta por Nicolás Casullo quien en «Historia y memoria», ensayo aparecido en el libro Las cuestiones, ha dividido en tres etapas sucesivas el período posdictatorial en que se fueron desplegando los diferentes discursos o narrativas sobre los años 70 y el proyecto de exterminio que estuvo a cargo del Estado militar (Casullo). ${ }^{2}$ Esta periodización permite poner en relación cada uno de los momentos donde se evidencian diferentes planteos respecto a los discursos sobre la dictadura, la militancia y la lucha armada, con reacomodamientos que se producen en el campo literario producto de exigencias políticas y de los retos que la transnacionalización de la edición, o el imperio de una lógica comercial genera al interior del mismo. Así, la puesta en contacto entre la serie de novelas publicadas sobre la dictadura y los mecanismos de promoción, determinó el siguiente corpus de trabajo:

- Período 1983-1994

- Dal Masetto, Antonio. Fuego a discreción. Premio Municipal Buenos 1983.

- Giardinelli, Mempo. Luna Caliente. Premio Nacional de Novela México 1983.

- Gusmán, Luis. En el corazón de junio. Boris Vian 1983.

- Casullo, Nicolás. El frutero de los ojos radiantes. Folios, 1984. Premio Pablo Poblet 1989.

- Lopez, Fernando. El mejor enemigo. Premio Latinoamericano de Narrativa Universidad de Colima, México, 1984.

- Di Bendetto, Antonio. Sombras nada más. Premio Boris Vian 1985.

- Rivera, Andrés. En esta dulce tierra. Segundo Premio Municipal 1985.

- López, Fernando. Arde aún sobre los años. Premio Casa de las Américas 1985.

- Cedrón, Aníbal. La memoria extraviada. Mención Casa de Las Américas 1985.

- Martini, Juan Carlos. El fantasma imperfecto. Beca Gugenheim 1986.

- Roffé, Reina. La rompiente. Bienal Internacional de Novela Breve para obras en castellano Municipalidad de Córdoba 1986.

- Kozameh, Alicia. Pasos bajo el agua. Premio Revista «Crisis» por el quinto capítulo 1986.

- Rabanal, Rodolfo. La vida brillante. Premio Municipal de Literatura Ciudad de Buenos Aires 1988.

- Paoletti, Mario. Antes del diluvio. Premio Castilla La Mancha 1988. 
- Amato, Ada. De cómo se amaron el Salvador y la Celeste. Premio Clarín Aguilar 1989.

- Martini, Juan Carlos. La construcción del héroe. Premio Municipal de Literatura Ciudad de Buenos Aires 1989.

- Ortiz, Carmen. El resto no es silencio. Seleccionada para la promoción de la literatura de Asia, África y América Latina, De Frankfurt para su traducción al alemán 1990.

- Martini, Juan Carlos. El enigma de la realidad. Premio Boris Vian 1991.

- Rivera, Andrés. La revolución es un sueño eterno. Premio Nacional de Novela 1992.

- Giardinelli, Mempo. El santo oficio de la memoria. Premio Rómulo Gallegos 1993.

- Paoletti, Mario. A fuego lento. Premio Quinto Centenario 1993.

- Sánchez, Matilde. El dock. Finalista Premio Planeta 1993.

- Período 1994-2004

- Stamadianos, Jorge. Latas de cerveza en el Río de la Plata. Premio Emecé 1994.

- Strejilevich, Nora. Una sola muerte numerosa. Premio Letras de Oro, Literary Prize (USA), bienio 1995-1996, Finalista Premio Planeta 1997.

- Demitrópulos, Libertad. El río de las congojas. Boris Vian 1997.

- Martínez, Dámaso. El informante. Fondo Nacional de las Artes 1997 y Eduardo Mallea del Ciudad de Buenos Aires 1998.

- Rivera, Andrés. El verdugo en el umbral. Premio Club de los XIII 1995.

- Franz, Carlos. El lugar donde estuvo el paraíso. Primer Finalista Premio Planeta 1996.

- Vitagliano, Miguel. Los ojos así. Premio Anna Segehrs 1996.

- Nielsen, Gustavo. La Flor Azteca. Finalista Premio Planeta 1997.

- Vieytes, Raúl. Kelper. Mención Premio Clarín de Novela 1999.

- Gorostiza, Carlos. Vuelo de palomas. Premio Planeta 1999.

- Solá, Marcela. El silencio de Kind. Finalista Premio Planeta 1999.

- Sagastizábal, Patricia. Un secreto para Julia. Premio La Nación 1999.

- Osorio, Elsa. A veinte años Luz. Premio Amnesty International 1999 y finalista Premio Fémina 1999.

- Scliar, Liliana. La arquitectura de los ángeles. Premio Planeta 2000.

- Saccomanno, Guillermo. El buen dolor. Premio Nacional de Novela 2000.

- Feijoó, Cristina. Memorias del río inmóvil. Premio Clarín de Novela 2001.

- Andruetto, María Teresa. La mujer en cuestión. Primer Premio Fondo Nacional de las Artes 2003.

- Dupont, Mariano. Aún. Premio Emecé 2003.

- Neumann, Andrés. Una vez Argentina. Finalista Premio Herralde de Novela 2003.

- Período 2004-2014

- Fogwill, Rodolfo. Vivir afuera. Premio Nacional de Literatura 2004 y Premio Elia Kalish mejor novela de los 90.

- López, Fernando. La odisea del cangrejo. Finalista del Premio Planeta 2004.

- Mallo, Ernesto. La aguja en el pajar. Finalista Premio Clarín-Alfaguara y Premio Memorial. Silverio Cañada. Semana Negra de Gijón en 2011 con el título Crimen en el barrio del Once.

- Franz, Carlos. El desierto. Premio La Nación-Sudamericana de Novela 2004-2005. 
- Argemí, Raúl. Penúltimo nombre de guerra. Premio Hammet, Semana Negra de Gijón 2005.

- Kaufman, Paola. El lago. Premio Planeta 2005.

- Almeida, María Eugenia. El colectivo. Premio Novela Las dos orillas 2005.

- Monacelli, Fernando. La mirada del ciervo. Finalista Premio Clarín-Alfaguara 2005 y La

Nación. Emecé 2006.

- Kohan, Martín. Dos veces junio. Finalista Premio de Literatura Internacional, Casa de la Cultura de Berlín 2009.

- Rodríguez, Cristian. Madrugada negra. Premio Novela Biblioteca Nacional 2007.

- Huidobro, Norma. El lugar perdido. Premio Clarín de Novela 2007.

- Kohan, Martín. Ciencias Morales. Premio Herralde 2007.

- Mercado, Tununa. Yo nunca te prometí la eternidad. Premio Sor Juana Inés de la Cruz 2007.

- Feijoó, Cristina. La casa operativa. Finalista Premio Planeta 2007 y Afuera. Primer Certamen Internacional de la Editorial Punto y Aparte 2008.

- Robles, Raquel. Perder. Premio Clarín de Novela 2008.

- Busqued, Carlos. Bajo este sol tremendo. Finalista Premio Herralde de Novela 2008.

- Krimer, María Inés. Lo que nosotras sabíamos. Premio Emecé 2009.

- Neumann, Andrés. El viajero del siglo. Premio Alfaguara 2009.

- Sacommanno, Guillermo. 77. Premio Dashiel Hammet 2009.

- Orsi, Guillermo. Ciudad Santa. Premio Dashiel Hammet 2010.

- Saccomanno, Guillermo. El oficinista. Premio Biblioteca Breve Seix Barral 2010.

- Andruetto, María Teresa. Lengua Madre. Finalista Premio Rómulo Gallegos 2011

- Lozano, Luis. El imitador de Dios. Premio Clarín 2011.

- Pasquini, Gabriel. Padres de la Patria. Finalista Premio Herralde de Novela 2011.

- Piglia, Ricardo. Blanco nocturno. Premio Rómulo Gallegos y Dashiel Hammet 2011.

- Monacelli, Fernando. Sobrevivientes. Premio Clarín de Novela 2012.

- Brizuela, Leopoldo. Una misma noche. Premio Alfaguara 2012.

- González, Betina. Las poseídas. Premio Tusquets de Novela 2012.

- Gómez, José María. Los marianitos. Mención especial Premio Internacional de novela Letra Sur 2014 .

\section{b) Novelas premiadas y transnacionalización de la edición en números}

La trasnacionalización de la edición, en función de los réditos económicos, propició la publicación y premiación de novelas sobre la problemática dictatorial. El siguiente gráfico revela el aspecto cuantitativo de la relación entre las novelas publicadas y las novelas galardonadas:
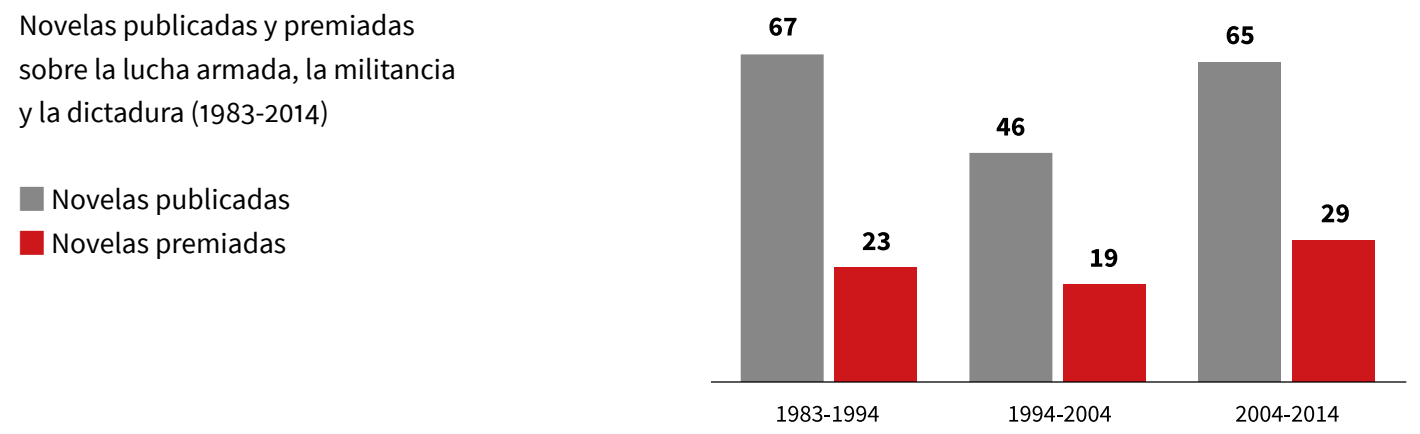
En principio, el gráfico muestra un ritmo constante y recurrente de premiación de novelas sobre la dictadura en el arco temporal de 31 años, pero este proceso no es uniforme ya que en el segundo período se evidencia una marcada disminución del número de novelas publicadas, 46 en oposición a las 67 del primero y 65 del tercer período. Esta disminución en el número de novelas editadas daría cuenta de los efectos de las políticas de «reconciliación»y «pacificación» que se alentaron desde el gobierno de Carlos Menem con la sanción de las leyes de Punto final y Obediencia Debida. Sin embargo, si se observan los números de novelas laureadas, se advierte un crescendo en la premiación de novelas, siendo la década 2004-2014 con 29, la que galardonó mayor cantidad de ficciones, frente a las 23 y 19 de las décadas anteriores. Este mayor interés en la coronación de novelas sobre el poder dictatorial, estaría relacionada con un retorno de la problemática de los derechos humanos, alentado desde el gobierno por gestos concretos como el retiro de los retratos de los represores en el Colegio Militar de la Nación y la nulidad de las leyes de Obediencia Debida y Punto Final. En el cruce, entonces de transnacionalización de la edición, con su sistema de premios literarios, y política de la memoria kirchnerista se narró el pasado reciente y su relación con el presente.

Ahora bien, si se analiza la variable del porcentaje de novelas premiadas, se consignan los siguientes datos, sobre el total de 71:

Porcentaje de novelas premiadas por decenio

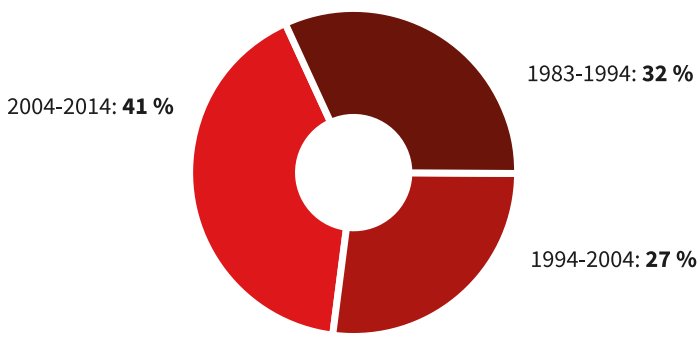

Este gráfico donde se consigna el porcentaje de novelas laureadas por decenios, muestra con mayor claridad no sólo el ritmo constante respecto a la premiación de novelas sobre la lucha armada, militancia y dictadura sino también el aumento de galardones en el último período y, además, se visualiza la desaceleración en el ritmo de premiación en el segundo período, asociada como se explicó anteriormente a las «políticas de pacificación» del gobierno menemista.

El porcentaje de la primera década estaría en consonancia con lo que libreros y editores definieron en cuanto a los intereses de los lectores. En términos generales, según Natu Poblet, entre 1983 y 1984 hubo un gran interés por los asuntos históricos-políticos desencadenados por dos grandes cuestiones nacionales: Malvinas y la represión y desaparición de personas. La demanda de literatura política se asemeja a la que se verificó del 72 al 74 (Poblet:6). Sin embargo, si la apertura democrática fue favorable política y culturalmente para temáticas relacionadas con el pasado reciente, no lo fue desde el punto de vista económico ya que el sector editorial estaba venido a menos: «Imagine que, antes de este período, una tirada de 5000 mil ejemplares se vendía en 15 días; actualmente una explosión de esas se dio casi exclusivamente con la edición del Nunca Más» (6). Por su parte, Luis Gregorich confirma lo anterior, ya que a su juicio el público de la Argentina democrática está interesado por el pasado reciente y por las crónicas esclarecedoras de los sucesos acaecidos. El informe de la CONADEP se había convertido en el libro más vendido desde hacía mucho tiempo (Gregorich:4). De manera que se puede concluir que durante esta década, si bien el aspecto 
cultural ofrece posibilidades asociadas a la apertura del régimen democrático y la supresión de la censura, lo que limita dichas posibilidades es la retracción económica provocada por la falta de medios para adquirir libros y la dificultad para trazar planes ambiciosos por parte de las casas editoras por la presión inflacionaria (Cesarotto:11).

Finalmente, el porcentaje de la última década indicaría, como ya se explicó, el momento de mayor interés desde los mecanismos de consagración por la problemática, posiblemente alentado por una política de la memoria estatal que se centró en los efectos de la dictadura. La memoria acuñada por los Organismos de Derechos Humanos se volvió memoria oficial, es decir, se convirtió en la política de derechos humanos del propio Estado. La renovación de las cúpulas militares, la anulación de las leyes del Perdón y del decreto que inhibía la posibilidad de extraditar militares para ser juzgados, la declaración del 24 de marzo como feriado inamovible, la cesión del predio de la ESMA a Organismos de Derechos Humanos son algunas de las medidas llevadas a cabo durante la década kirchnerista las cuales generaron nuevas condiciones para la recepción social de la problemática de la violación de los derechos humanos. El hecho de que el tema comenzó a ser tratado sistemáticamente en diversos medios y por actores políticos que en épocas pasadas no habían mostrado interés en este asunto, produjo cierta banalización ya que abrazar esta memoria representaba una señal necesaria a un liderazgo político con lo cual se convirtió en un objeto instrumental que nada decía de la relación de estos actores con el pasado reciente. En este sentido, se instalaría una pregunta acerca de los riesgos de un «esclerosamiento» de la memoria de la represión al haberse tornado hegemónica.

Ahora bien, la relación entre premios literarios y novelística sobre la dictadura se complejiza cuando se ahonda en la lectura de los textos puesto que en novelas laureadas y no laureadas hay un recurrencia a la problemática de los galardones literarios. Muchas de las novelas incorporan el mundo de los premios literarios en su propia trama y fábula. Así, las ficciones se constituyen en un reverso de los discursos de legitimación, un lugar donde los mecanismos de premiación pueden ser leídos a partir de situaciones narrativas donde se configuran sentidos en torno al funcionamiento de los premios y la relación con la problemática dictatorial como la colaboración civil, la represión y la tensión entre recompensa material y simbólica que los premios literarios siempre han planteado, especialmente en momentos donde predomina en el campo cultural una lógica regida por las cifras de venta.

Así, es en torno a la figura de Borges donde se engarzan aspectos que denuncian la relación entre mecanismos de premiación y colaboración civil. En la novela Fuego a Discreción (1985), a través de una ironía que alude a la denegación del Premio Nobel a Jorge Luis Borges, como la alusión al almuerzo que este autor tuvo con Videla, junto a la denuncia de la SADE, en 77 de Guillermo Saccomanno ${ }^{3}$ y en Una misma noche de Leopoldo Brizuela, se reconstruye no sólo el contexto cultural y literario dominante en el campo de la literatura argentina del momento sino también destaca el carácter cívico militar del eufemísticamente llamado «Proceso de reorganización nacional», a través de la denuncia a las instituciones y escritores que colaboraron.

Un autor que ha aludido recurrentemente en sus novelas, laureadas y no laureadas, a los certámenes literarios asociado a la problemática dictatorial, fue Rodolfo Enrique Fogwill. ${ }^{4}$ En La experiencia sensible (2001), Fogwill no sólo compara la entrega de recompensas artísticas con el juego, lo cual destacaría la arbitrariedad que se encuentra en su base sino que también resalta el carácter de marketing que da origen a todo premio, el cual siempre genera ganancia a quien lo organiza. En 
Vivir afuera (2003), a través de un monólogo interior, Wolf, el personaje alter ego de Fogwill, piensa en una idea para presentar un ensayo en un concurso del diario La Nación. La necesidad de adaptar una temática a las bases de un certamen muestra el aspecto represivo que ejercen los galardones sobre el trabajo creativo del escritor. Este aspecto restrictivo de los premios aparece también en una novela no premiada Un guión para Artkino, donde el Estado censura obras mientras que en Sobre el arte de la novela (1993) aparecen los pensamientos de un autor que está escribiendo una novela sobre Malvinas para un concurso. En este caso, el premio estaría al servicio del proyecto narrativo de Fogwill. Las diferentes alusiones a los premios literarios en las novelas de este autor se pueden leer no sólo como parte de una estrategia refinada y anómala de propaganda, de «autoproducción pública» (Cristófalo) sino también en estrecha relación con la particular concepción respecto de la dictadura. Para este autor la herencia del «proceso» fue la represión cultural «verificada sin censura, sin persecuciones ni "listas negras", con el sencillo recurso de una "lista blanca" de temas y palabras que entusiasman a un público, que como siempre necesita dormir entre los sueños que distribuye la cultura» (Fogwill:65). Y esto se constituyó, según el autor, en un negocio limpio de la industria cultural. En síntesis, la constante presencia temática de los mecanismos de premiación en la novelística de Fogwill desenmascara los efectos promocionales en una sociedad autoritaria que propicia el éxito financiero en La experiencia sensible, como mecanismo de censura y el adoctrinamiento en la sociedad comunista de Un guión para Artkino. También deja al descubierto la figura del escritor sometido a bases y características de los concursos en Sobre al arte de la novela (1983). En ambas direcciones, la reflexión está entramada con una postura crítica no sólo relacionada con las exigencias del mercado sino con la relación, a veces velada, entre dictadura y mercado cultural.

Finalmente, en un campo literario que favorece la denegación de lo material, el aspecto que se rescata con mayor asiduidad es el simbólico, como en Lo que nosotras sabíamos (2009) de María Inés Krimer, donde a través de un chisme se sabe que Norma, la escritora amateur, ha ganado un premio en España que la compensa ante tanta desgracia y pérdida, ${ }^{5}$ o en Lengua Madre (2010) donde la escritura de Doris Lessing, ganadora del Premio Nobel, será el objeto de estudio de la tesis doctoral de Julieta Proieto, ${ }^{6}$ uno de los personajes principales de la novela. No obstante, hay otras voces que abordaron y focalizaron el aspecto material que conlleva la consagración literaria o la relación literatura y dinero como en Una misma noche (2011) de Leopoldo Brizuela. El escritor Leonardo Bazán alterna la investigación para escribir una novela sobre el Caso Papel Prensa, con las múltiples actividades, «changas», que debe desempeñar el escritor para vivir, tales como dar clases, coordinar tecnicaturas y ser jurado de concursos, en este caso de un concurso de cuentos «Adolfo Bioy Casares» organizado por la Municipalidad de Las Flores. En efecto, la novela focaliza en la actividad del tribunal evaluador, en sus reuniones previas, y en el momento de la entrega de premios. Así, desde el punto de vista de los jurados, estos no aparecen leyendo o evaluando trabajos sino que pone en escena los encuentros y la relación con los pares lo cual vehiculiza la concepción de un jurado como un cuerpo homogéneo de trabajadores que comparten una misma labor, caracterizada por una identidad profunda derivada de la práctica narrativa donde gustos, formación y opiniones críticas específicas, propias de la tarea narrativa, facilita el consenso. ${ }^{\urcorner}$Por otra parte, el hecho de que se reúnan en un bar y no en dependencias del municipio y que los jurados conversen en el viaje sobre literatura, garantiza profesionalismo, transparencia, autonomía e independencia del tribunal respecto a posibles presiones originadas en los organizadores. ${ }^{8}$ Otro aspecto que se destaca de los premios tiene que ver con la posibilidad de que a partir de estas actividades se puede 
viajar y conocer gente, en tanto en la novela los jurados reciben invitación del intendente para visitar la iglesia de Las Flores donde se habían casado "Adolfito» Bioy Casares y Silvina Ocampo, con Borges y Drago Mitre por testigos; y un día después, «a la célebre estancia de los Bioy». En estos ejemplos emerge la imagen de un escritor feliz con su tarea y que disfruta de la compañía de sus pares a pesar de las diferencias de intereses. Ahora bien, desde el punto de vista del jurado, vive la entrega de premios como un momento irreal ya que se pone en primer plano el aspecto simbólico y se deniega lo material. Define a los certámenes como «esa costumbre de los pueblos» y a los participantes como seres «contentos de haber cumplido con el deber». Por otra parte y siempre en relación con los premios, esta novela establece una conexión de intertextualidad con otra novela premiada, El silencio de Kind de Marcela Solá, finalista del premio Planeta 1999, donde una célebre pianista se aviene a tocar para un militar golpista, más precisamente, un militar alemán, con la esperanza de quedar a solas con él y preguntarle acerca de su hermana desaparecida: «Investigar sobre esa escena me llevó a imaginar el resto de la novela» (Brizuela:s/p). En el caso de Brizuela, la trastienda de los premios permite tejer el entramado intertextual en función de recordar y poder representar el horror. Esto indica que las novelas premiadas respecto a esta temática constituirían un almacenamiento o depósito de bienes simbólicos, una reserva de representaciones sobre la problemática a la que todo escritor, como en el caso del personaje del relato, puede recurrir.

Finalmente, Ricardo Piglia en Blanco Nocturno (2011), pone el acento en el aspecto competitivo y en la vertiente económica de los galardones literarios, a través de un comentario que expresa Bravo, el cronista de sociales. En efecto, el periodista le cuenta a Renzi que en su juventud había sido un excelente jugador de tenis pero que su carrera había sido interrumpida por una lesión en la mano de la que nunca se había podido recuperar, entonces, le confiesa a Renzi que cuando necesita dinero, se va a jugar a la paleta contra los paisanos que no lo conocen y a quienes siempre les ganaba: «No hay nada más diferente a una cancha de tenis que un frontón de pelota vasca, pero la clave sigue siendo ver la pelota y la vista no la he perdido y puedo jugar de zurda, con la mano atada. En Cañuelas le gané a Utge — dijo como si le hubiera ganado un concurso de poesía a William Shakespeare» (126).

Si bien la alusión a los premios literarios es breve, se encuentra asociada al deporte, la competencia y el dinero. Esta alianza no está ajena a las declaraciones de Piglia respecto a los certámenes literarios. Para este autor, los premios establecerían una jerarquía ya que habría un escritor número uno, dos, tres o cuatro, posible en el deporte pero imposible para la literatura. Por ello, los premios generarían incomodidad y no legitimarían la obra de un escritor. Sin embargo, según Piglia, el establecimiento de un orden, «sería una tentación del mercado que intenta ordenar lo que la cultura desordena o pone en crisis» (s/p), y por ello tiende a proponer uno o dos escritores por país y toma a los premios como una definición.

Ahora bien, la problemática de los certámenes literarios enlazada con novelas sobre la militancia, la lucha armada y la dictadura aparece con claridad en una novela no premiada cuyo título genera confusiones. En Médanos/Premio de Narrativa Hispanoamericana (2010), de Gustavo Kusminsky, en la cual se narran dos historias. Una es la de Marcos, un escritor que gana un premio literario arreglado y decide simular su propia muerte, como parte de la construcción de su nombre. Y otra, la de otro Marcos, cuya historia transcurre durante el año 1978 en medio de la alegría futbolera mundialista que disimula el horror de la dictadura y que a pedido de su tío, también Marcos, exiliado en México, viaja al pueblo de Médanos para conocer el origen de su familia. 
Las dos historias se desarrollan con cierta independencia, pero se chocan, se alejan, se buscan, se anulan, se potencian (Kusminsky:s/p), se encastran a través de la presencia de personajes con el mismo nombre, Marcos, los cuales no sólo son personajes diferentes, sino que se imaginan mutuamente. La novela enseña paso a paso cómo se construye un nombre en el campo literario actual. Primero hay que adaptarse a las reglas y aceptar el premio arreglado. Luego muestra lo que Raymond Williams (1981) ha destacado como «la interiorización de las reglas del mercado en la mano que escribe», ${ }^{9}$ ya que revela los pasos a seguir especialmente en el momento de escribir la novela premiable: respetar la normativa del certamen y abordar una temática que interese, a través de un género estimado. En nuestro país, Kusminsky sugiere que para que una ficción sea coronada debe estar relacionada con la historia reciente y, sobre todo, con la dictadura, porque esta forma parte del "catálogo de motivos literarios».10

Si en las novelas anteriores, la alusión a los premios estaba relacionada con aspectos como la complicidad civil, la recompensa material o simbólica en relación con el exilio o el «insilio», en esta novela se conectan galardones y temáticas aceptadas como la dictatorial. De este modo, respetando todas esas presiones o reglas, Kusminsky nos deja una didáctica de la adaptación o una pedagogía para la construcción de un nombre en La república mundial de las letras (Casanova 2001).

\section{c) Los consagradores}

En términos nacionales y regionales es necesario distinguir los agentes de premiación, esto es, qué «instituciones» (Williams 1994:187) están dotadas del poder de consagrar específicamente, novelas relacionadas con la temática dictatorial y en qué momento de los últimos treinta años predominan los diferentes agentes. Así se podrá comprender desde el punto de vista «institucional» la relación entre las instancias premiación, la problemática dictatorial y las exigencias surgidas por la transnacionalización del mercado editorial. En este sentido, se afirma que este proceso editorial ha afectado de diversos modos a un mecanismo de consagración de corte moderno. Según la investigadora Alejandra Laera (2014), en los años 90 se asistió a un cambio definitorio en la lógica de los premios literarios causado en el orden cuantitativo por la proliferación de instancias evaluativas (oficiales, institucionales, editoriales, mediáticas, locales, transnacionales, globales), y en el cualitativo por su diversificación (de la circunscripción propia de los premios oficiales dados a la trayectoria o a la obra del año). Especialmente, porque el premio literario se inició en la lógica del espectáculo, reservada a otros tipos de premios culturales (en general ligados al cine, y a los artistas) que reconvirtió los sentidos de su valor y modificó la escala de premiaciones según parámetros más vinculados a la circulación de los escritores y los libros que con la especificidad de la literatura y de los textos (Laera 2010:264).

Ahora bien, una de las dificultades para trabajar esta parte de la tesis fue poder analizar las instituciones que otorgaron galardones tomando un solo punto de vista, ya que no hay una clasificación única respecto a los premios literarios. Así, Nicole Witt clasifica a los certámenes en «oficiales» o «editoriales», «comerciales» o «no comerciales» (306). Por su parte, Guido Indij responsable de la editorial Interzona, ha realizado una categorización en cinco tipos de premios:

1. Los que funcionan como convocatoria de editores de vanidad, o sea, los que buscan contactar a los autores que quieren ser publicados con editoriales que eventualmente, publicarán un libro o una antología e intentarán cobrarles la publicación o todo el resto (Duken, Cuatro Vientos, etc.). 
2. Están los concursos bien organizados de editores serios, con reglamentos y jurados serios. Aunque uno puede inferir o sospechar que los resultados son tendenciosos y responden a intereses anteriores de esa editorial (Nadal, Herralde, Planeta, La otra orilla).

3. Los que presentan medios periodísticos aprovechando su capacidad de difusión (Clarín con Alfaguara, Página 12, etc.).

4. Los de organismos oficiales, también con mecanismos más o menos sofisticados. Algunos como el Biblioteca Nacional publican al ganador como ocurre con muchos premios municipales y otros, como los del Fondo Nacional de las Artes, subsidian la edición.

5. Finalmente, están los que premian a un autor o una obra a publicada (el Premio del Lector de la Feria del Libro, el Rómulo Gallegos, el Cervantes, el Nobel). (66)

Teniendo como horizonte estas dos clasificaciones, pero en consonancia con el corpus analizado, se consideraron:

1. Premios oficiales: a todos aquellos que están apoyados por entidades estatales, Premios Nacionales, Municipales, Biblioteca Nacional, Rómulo Gallegos, Casa de las Américas, Sor Juana Inés de la Cruz y de otras instituciones como el Letras de Oro (Literary Prize), Fondo Nacional de las Artes; Premio de narrativa de Colima.

2. Premios editoriales y multimediales: Planeta, Las dos orillas, Tusquets, Anagrama, Emecé, Clarín, Página 12, La Nación, etcétera.

3. Premios otorgados por los escritores o pares: Boris Vian, Club de los XII, Dashiel Hammet, Pablo Poblet.

4. Premio de lectores: el de blog como el Premio Elsa Kalish.

Ahora bien, la correlación de los certámenes enumerados con las novelas premiadas por cada una durante las tres décadas, arroja los siguientes datos: los premios oficiales galardonaron 28 novelas sobre la lucha armada, la militancia y la dictadura. Los premios editoriales y multimediales coronaron 34. Los premios de pares consagraron 11" y los de blog 1 novelas, según muestra el siguiente cuadro:

Novelas galardonadas según agentes

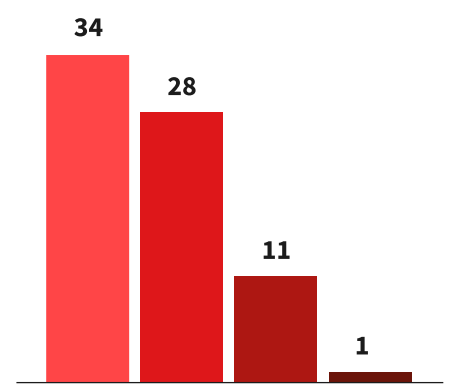

Premios editoriales y multimediales

Premios oficiales

Premios pares

Premios Blog

Sin embargo, si se tiene en cuenta el porcentaje, se obtienen las siguientes cifras: 
Porcentaje de novelas premiadas según agentes

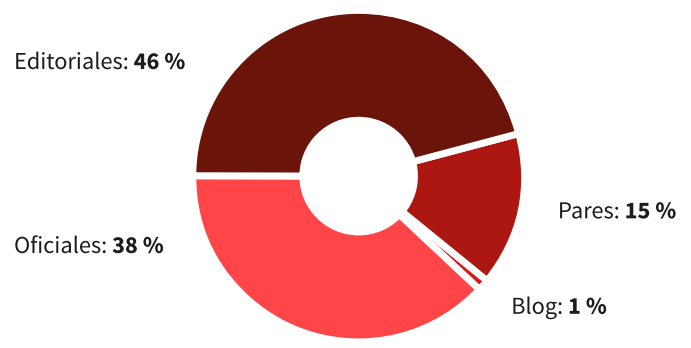

En conjunto se evidencia la actividad consagratoria de distintos agentes del campo literario argentino, como los son los premios otorgados por los escritores y la emergencia de una nueva modalidad de legitimación asociada con los medios digitales como los premios instituidos a partir de los blogs. Se puede observar que durante el período 1983-2014 operan con diferente poder consagratorio modos variados de premiación lo cual coincide con la evaluación realizada por Nora Catelli (2010), quien sostiene que, aunque los editores españoles o europeos fiscalicen el proceso editorial, en las distintas capitales, existe un poder consagración que disputaría en cuanto a la jerarquización del prestigio, la capacidad de control del mercado.

Desde el punto de vista específico de la ficcionalización de la problemática dictatorial, ésta ha sido legitimada, como se ha visto, desde distintas instancias consagratorias que conforman el sistema de premiación de la literatura argentina. Incluso se puede observar la emergencia de una nueva modalidad de premiación como la surgida de la actividad en la blogósfera por el desarrollo de las nuevas tecnologías ligadas al mundo digital.

El mayor interés por consagrar novelas sobre la dictadura emana de las empresas editoriales o multimediales que se opondrían a los premios oficiales u otros, por lo que se puede afirmar que la canonización de la temática dictatorial se encuentra fuertemente ligada al poder editorial y a su lógica comercial. Dentro del conjunto de premios editoriales y de empresas multimediales, el Premio Planeta y el Premio Clarín son los que han galardonado mayor cantidad de novelas con primeros premios y finalistas de narraciones sobre la lucha armada, la militancia y la dictadura. En efecto, si se tienen en cuenta las novelas premiadas y los premios según las décadas, se puede observar que durante el primer decenio los oficiales y los otorgados por pares son los que más han consagrado novelas sobre la militancia, la lucha armada y la dictadura; mientras que durante el segundo y tercero, si bien no desaparecen las premiaciones brindadas por organismos oficiales o de pares, la actividad consagratoria es desplegada marcadamente por los premios editoriales.

Una novedad en la serie de los agentes consagradores, la constituyen los premios de Blog como el premio del Blog Elsa Kalish que fuera otorgado a Vivir afuera de Rodolfo Fogwill, considerada la mejor novela de los 9o. Tal galardón da cuenta de la aparición de nuevos actores en el juego literario que según Sylvie Ducas (2013), modificarían, sin poder preverse aún, la incidencia sobre el estatus simbólico y la función social del escritor, las configuraciones y estrategias autorales. El desarrollo de sitios de escritores, los blogs de lectores, las redes sociales, los chats, los foros y otras formas de escritura colectiva provocaron una reinvención del lector con pretensiones autorales que cambiaron las reglas del juego del reconocimiento literario: la lógica de la excelencia deja lugar a una lógica de la afiliación fundada sobre una comunidad de gustos compartidos. En tensión con las instancias tradicionales fundadas sobre la prescripción vertical sostenida por una élite letrada coexisten estos premios, que presentan un modelo de prescripción horizontal, directa y más democrática y que están sostenidos por un ágora de jueces populares. En efecto, Internet 
reforzó y aceleró la promoción del juzgamiento amateur, dinamitó la frontera móvil que separaba a profesionales de amateurs, lo cual puso en cuestión la creencia colectiva en un juicio crítico capaz de designar la excelencia literaria. La lucha por imponer otra definición legítima de literatura es dictada por el «j'aime/j'aime pas» (Ducas 2013:141) de lecturas pasionales y por el interés puesto en los márgenes olvidados de la "sociedad del espectáculo». La blogósfera ofrece al lector salir de la sombra y existir plenamente en estas nuevas formas de sociabilidad como lector, actor, participante, al mismo tiempo que la web le ofrece estar en escena y mostrar su saber personal en una postura inédita de un lector que juzga y un lector «protoprofesional» (143). Esta postura es inseparable de una cultura literaria donde se construye la opinión entre cultura literaria y gustos personales que no excluye la dimensión ética de una palabra responsable, que sería además una especie de baliza y ayuda al consumo literario en un contexto de gran producción editorial.

El Premio Elsa Kalish responde a la descripción brindada por Ducas (2013), dado que es otorgado por un lector, no en un blog, sino a través de una revista digital: El interpretador. Desde diciembre de 2004 hasta 2005, Elsa Kalish, pseudónimo de Juan Pablo Liefeld, escribió en esa revista una columna mensual titulada "Las chicas de letras se masturban así» y, en oposición a lo sostenido en la carrera de Letras que consideran a Las islas, de Carlos Gamerro como la mejor novela de los 90, coronó a Vivir afuera como la narración más destacada de la mencionada década (Liefel:s/p).

La confrontación que aparece en la expresión de una «opinión no canónica en letras» manifiesta la tensión que conlleva legitimar obras literarias desde lecturas pasionales, guiados por criterios amateurs, como lo ha señalado Sylvie Ducas (2013). En general, los premios analizados en este apartado, como los otorgados por pares o lectores, no han sido pensados desde el marketing ni concebidos para la gran venta de ejemplares, sino que presentan las características de la consagración moderna, ya que consagran una obra publicada o un proyecto literario ya desarrollado; por ello, estos galardones como los premios nacionales, el Rómulo Gallegos, el Casa de las Américas tienen poco efecto en la esfera comercial: «no consiguen lanzar de manera contundente un libro o un autor» (Fagnani:70).

Finalmente, y en relación con la actividad consagratoria de los diferentes agentes, emerge un aspecto que debe tenerse en cuenta como el caso de multipremiación, ${ }^{12}$ es decir, de novelas que son doble y triplemente premiadas, fenómeno que se produce recurrentemente en aquellas galardonadas en certámenes organizados por las multinacionales de la edición que marcan el ritmo actual de coronación:

\begin{tabular}{|c|c|c|c|}
\hline AUTOR & NOVELAS & PREMIO & AÑo \\
\hline \multirow[t]{2}{*}{ Dámaso Martínez, Carlos } & El informante & Fondo Nacional de las Artes. & 1997 \\
\hline & & Premio Eduardo Mallea & 1998 \\
\hline \multirow[t]{2}{*}{ Strejilevich, Nora } & Una sola muerte numerosa & Letras de Oro (USA) & 1995-1996 \\
\hline & & Finalista Premio Planeta & 1997 \\
\hline \multirow[t]{2}{*}{ Osorio, Elsa } & A veinte años $L u z$ & Premio Amnesty Internacional & 1999 \\
\hline & & Finalista Premio Fémina & 1999 \\
\hline \multirow[t]{2}{*}{ Fogwill, Rodolfo } & Vivir afuera & Premio Nacional de Literatura & 2004 \\
\hline & & Elsa Kalish & 2005 \\
\hline \multirow[t]{2}{*}{ Monacelli, Fernando } & La mirada del ciervo & Finalista Premio Clarín Alfaguara & 2005 \\
\hline & & Finalista Premio La Nación Sudamericana & 2006 \\
\hline
\end{tabular}




Mallo, Ernest

Krimer María Inés

Piglia, Ricardo

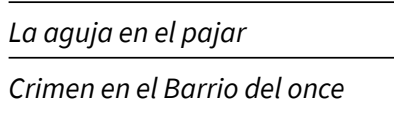

Lo que nosotras sabíamos

Blanco Nocturno

Finalista Premio Clarín Alfaguara
Premio Memorial Silverio Cañada Semana
Negra de Gijón

\section{Finalista Premio Clarín}

Premio Emecé

Premio de la Crítica

Premio Rómulo Gallegos

Premio Casa de las Américas de Narrativa José María Arguedas

\begin{tabular}{l}
\hline 2004 \\
\hline 2011 \\
\hline 2008 \\
\hline 2009 \\
\hline 2011 \\
\hline 2012
\end{tabular}

El cuadro permite analizar este fenómeno de multipremiación y la circulación de las novelas. Hay novelas que han recibido sólo premios oficiales como El informante, de Carlos Dámaso Martínez, que fue coronada por el Fondo Nacional de las Artes (1997) y por el Premio Eduardo Mallea (1998); mientras otras sólo han sido valoradas en el circuito internacional como A veinte años Luz, de Elsa Osorio que fue condecorada con el Premio Amnesty Internacional (1999) y fue finalista del Premio Femina (1999); la novela Vivir afuera de Rodolfo Fogwill fue distinguida con el Premio Nacional de literatura (2005) y por Elsa Kalish (2005). Existe el caso de novelas que son finalistas en dos premios editoriales como La mirada del ciervo, de Fernando Monacelli que en 2005 fue finalista del Premio Clarín-Alfaguara y en 2006, finalista de La Nación Sudamericana o casos como el de María Inés Krimer en que Lo que nosotras sabíamos es finalista del Premio Clarín (2008) y al año siguiente es ganadora del Premio Emecé lo cual da cuenta de la circulación de premio en premio de los mismos manuscritos, característica actual del mundo de los galardones, dado que para muchos autores no sólo es el único modo de ingresar al juego literario sino también de sustento económico. En esta serie de novelas multipremiadas la que mayor cantidad de distinciones fue acumulando a lo largo de tres años fue Blanco Nocturno, de Ricardo Piglia, laureada con el Premio de la Crítica en 2010, el Rómulo Gallegos y el Dashiell Hammett, ambos en 2011, y el Premio Casa de las Américas de Narrativa José María Arguedas en 2012. Si se analizan los premios recibidos se evidencia una consagración de carácter regional y otorgada por los pares. Emerge, también, el poder consagratorio peninsular dado que el primer galardón recibido es español.

\section{d) Los premiados}

Cuando se observa en el corpus la lista de autores premiados, se evidencia una variación, según cada década, en cuanto a la legitimación de autores y sus proyectos creativos. En el primer período predominan instancias de reconocimiento, oficiales o regionales y, en consecuencia, se galardonan preferentemente autores que estuvieron en el exilio, en muchos casos con obras que narraban el destierro. En el segundo período, comienzan a sentirse los efectos de la transnacionalización de la edición por lo que la tendencia disminuye. Se premian autores que vivieron en el exilio, muchos de ellos militantes de los derechos humanos, pero aparece la tendencia a premiar escritores jóvenes que se educaron o fueron adolescentes bajo la dictadura y que padecieron los efectos de la misma (Ruiz). En el último período, con la preponderancia de mecanismos de premiación ligados a conglomerados editoriales, se laurean proyectos creativos relacionados con la dictadura de autores inéditos o desconocidos. 
Los autores galardonados que estuvieron en el exilio laureados, por década y por orden alfabético, son:

- Primera década:

\section{AUTOR}

\begin{tabular}{l}
\hline Casullo, Nicolás \\
\hline Cedrón, Aníbal \\
\hline Di Benedetto, Antonio \\
\hline Giardinelli, Mempo \\
\hline López, Fernando
\end{tabular}

López, Fernando

Kozameh, Alicia
Martini, Juan Carlos

Martini, Juan Carlos

Ortiz, Carmen

Paoletti, Mario

Roffé, Reina

\section{- Segunda década}

\section{AUTOR}

Feijoó, Cristina

Osorio, Elsa

$\overline{\text { Sagastizábal, Patricia }}$

Solá, Marcela

Strejilevich, Nora

\section{- Tercera década}

\section{AUTOR}

Feijoó, Cristina

López, Fernando

Mercado, Tununa
TÍTULO

El frutero de los ojos radiantes

La memoria extravida

Sombras nada más...

Luna Caliente

El mejor enemigo

Arde aún sobre los años

Pasos bajo el agua
El fantasma imperfecto
La construcción del héroe
El enigma de la realidad

El resto no es silencio

A Fuego Lento

La rompiente

TÍTULO

Memoria del río inmóvil

A veinte años $L u z$

\begin{tabular}{l}
\hline Un secreto para julia \\
\hline El silencio de Kind \\
\hline Una sola muerte numerosa
\end{tabular}

AÑo

AÑo

1986

1985

1985

1983

1984

1985

1986

1986

1989

1991

1990

1993

1986

2001

1999

1999

1999

1996
PREMIO

Pabo Poblet

Mención Casa de las Américas

Boris Vian

Premio Nacional de Novela de México

Premio Latinoamericano de Narrativa Universidad de Colima.

Premio Casa de las Américas

\section{Revista Crisis}

Beca Gugenheim

Premio Municipal de Literatura Ciudad de Buenos Aires Boris Vian

Selección para la promoción de la literatura de Asia, África y América Latina

Premio Quinto Centenario

Bienal Internacional de Novela Breve Municipalidad de Córdoba

PREMIO

Clarín

Premio Amnesty International y Finalista Premio Fémina.

La Nación

Finalista Premio Planeta

Premio Letras de Oro Literay Prize. 
Los datos que surgen son a partir del cruce entre autores premiados y aquellos que estuvieron en el exilio es el siguiente:

Autores premiados que estuvieron en el exilio

Autores premiados

Autores exiliados

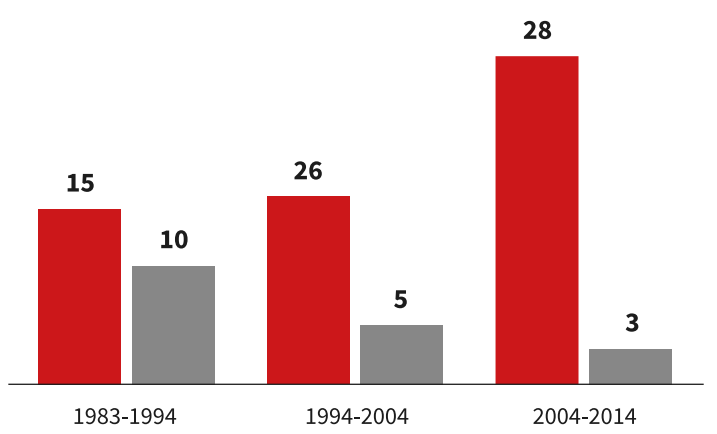

Del total de los autores exiliados, volcados en porcentaje se obtiene:
Porcentaje de autores premiados que estuvieron en el exilio

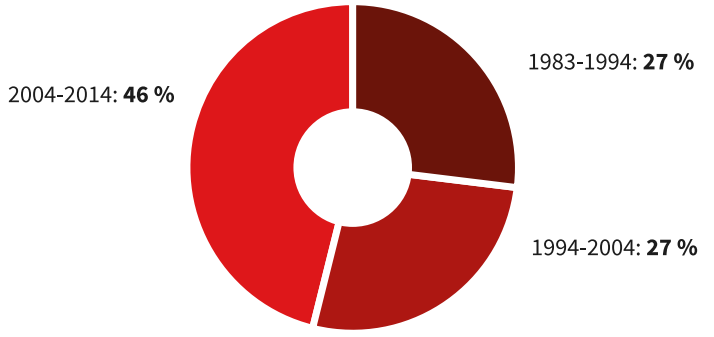

Los cuadros dan cuenta de las variaciones en cuanto a la selección de autores que van de la mano de las transformaciones que se produjeron en el campo literario argentino fruto de la transnacionalización de la edición. Durante la primera década fue galardonado un gran número de escritores ( $48 \%$ ) que vivieron en el exilio. Esto habilita a focalizar en dos cuestiones. La primera estaría relacionada con un aspecto «generacional» debido a que estos autores ya circulaban en la literatura argentina, es decir, habían publicado previamente, al menos un texto, antes del golpe de Estado de 1976. Otro aspecto que emergería de la lectura de estos cuadros, se relacionaría con el hecho de que las fuerzas dominantes que conformaban el campo literario nacional entre 1983 y 1994, estuvieron orientadas no sólo a hacer conocer las obras y autores que habían producido narrativas en el exterior o en el país durante los tiempos dictatoriales, sino también a dar unidad al campo literario que se encontraba dividido entre «los que se quedaron" $\mathrm{y}$ «los que se fueron».

En la segunda década se observa una disminución notable, pero no la ausencia, de la coronación de autores que experimentaron el destierro. Esto tendría que ver con un recambio generacional, con la entrada al juego literario de un conjunto de autores que, a pesar de las dificultades que debieron enfrentar a causa de las transformaciones generadas por el predominio de una lógica mercantil en la vida literaria argentina, presenta algunas características comunes sin que se pueda hablar de "generación». Vivieron su infancia y temprana adolescencia y recibieron la educación formal bajo la dictadura y comenzaron a definir sus proyectos creativos en pleno auge del neoliberalismo y de la transnacionalización de la edición lo que sembró de obstáculos el camino hacia la publicación. Gustavo Nielsen, Raúl Vieytes, Mariano Dupont y Andrés Neumann tenían entre nueve y quince años al producirse el golpe de Estado, por lo tanto, no participaron de la militancia 
activamente, carecían de formación política y muchos de ellos no tenían cabal conciencia de la represión indiscriminada, la censura y la muerte (Ruiz:50). Este plantel de novelistas al que se podrían agregar autores que lograron galardones en la siguiente década como Martín Kohan y Leopoldo Brizuela, recibieron su educación formal en una escuela fuertemente autoritaria en la que se reglamentaba hacia afuera desde la vestimenta al corte de pelo, y hacia adentro la implementación de una currícula imperativa y rígida; además iniciaron su proyecto creador al calor del neoliberalismo, cuando las editoriales dejaron de interesarse por la producción de escritores locales, situación que se agravó después de la crisis de 2001 (50). Asimismo, este elenco de escritores estuvo marcado no sólo por la experiencia dictatorial, sino también por la Guerra de Malvinas, hecho que se visualiza en sus obras si se recuerdan La flor azteca de Gustavo Nielsen o Kelper de Raúl Vieytes.

Ahora bien, respecto a autores que estuvieron en el exilio, es debe destacar que en esta década, son todas escritoras las galardonadas, con lo que se evidencia la consolidación de una tendencia que emerge en la década del 90 caracterizada por la presencia de textos escritos por militantes mujeres con novelas que presentan fuertes marcas testimoniales, en donde se aborda precisamente la militancia y los efectos de la dictadura como la desaparición de personas, la búsqueda de identidad y la problemática de la «adaptación» a la exigencias de una sociedad basada en el éxito y la fama.

Se trata de una literatura indeleblemente marcada por los "procesos» militares y dictatoriales en el Cono Sur entre 1970 y 1980. A partir de entonces la problemática de la dictadura y la actitud de las mujeres en relación con el poder de Estado y con la guerrilla, con los derechos humanos y la búsqueda de desaparecidos sobre todo a través de la emblemática figura de las Madres de Plaza de Mayo, comienzan a ocupar un lugar central en la narrativa femenina. El resto no es silencio (1989) de Carmen Ortiz que resulta galardonada, Reina Roffé con La Rompiente (1993) y Kozameh Alicia con Pasos bajo el agua (1987) constituyen una configuración posible en las representaciones y percepciones en el marco de la guerrilla y el terrorismo de Estado. Marta Traba con Conversaciones al sur (1981), sería una de las fundadoras de esta corriente que incluye nombres como el de Luisa Valenzuela, con sus libros Cambio de armas (1982) y Cola de lagartija (1983), Jorgelina Loubet con Los caminos (1981), y más recientemente El Dock (1993) de Matilde Sánchez y El fin de la historia (1996) de Liliana Hecker.

Por su parte, Gloria Pampillo presentó un trabajo titulado «La representación de la violencia de la dictadura en la narrativa de las mujeres argentinas» en el ciclo realizado en 2004, en el Centro Cultural Ricardo Rojas, cuyas ponencias fueron publicadas en Lo que falta y lo que sobra (en los últimos veinte años de la literatura argentina). Allí, la escritora señala que en los trabajos críticos acerca de la dictadura hay poca alusión a novelas escritas por mujeres. A raíz de ello, se pregunta cuál fue la razón por la cual en la crítica literaria argentina posterior al proceso fue tan poco considerada la ficción escrita por mujeres sobre un período histórico en el que fueron militantes, víctimas y, además, propulsoras de las primeras resistencias contra la dictadura. En este sentido, el emblema de la resistencia lo constituyen las Madres de Plaza de Mayo. Pero frente a esta ausencia, Pampillo afirma que en los últimos años esta tendencia se revierte en relación con la publicación, las premiaciones y la circulación editorial. En efecto, varias novelas de mujeres sobre la época de la dictadura y sus secuelas alcanzan prestigio ya sea por su circulación internacional o por los premios que ganan. Ejemplo de este cambio es la novela ya comentada anteriormente, $A$ 
veinte años Luz de Elsa Osorio, que no fue aceptada por las editoriales argentinas y fue publicada en España en 1999 y traducida a varias lenguas. También en 1999, El silencio de Kind de Marcela Solá es finalista del premio Planeta y recibe muy buena acogida de la crítica; Un secreto para Julia de Patricia Sagastizábal publicada por Sudamericana, es Premio La Nación 1999; Memorias del río inmóvil de Cristina Feijoó, ganadora del premio Clarín 2001. Para Pampillo este fervor es tan preocupante como aquella ausencia. Señala que en editoriales que no forman parte de los grandes holdings de capitales extranjeros comienzan a circular de forma más restringida las obras de Carmen Ortiz, Alicia Kozameh, Marta Vasallo, Alicia Partnoy, Nora Strejilevich y Cristina Feijoó. Esta tendencia que preocupa a Pampillo tiene ecos en un artículo de Hernán Arias en el que a partir de la premiación de Norma Huidobro con el Premio Clarín 2007 recuerda que esta escritora se suma a la creciente lista de mujeres de mediana edad que en las últimas siete entregas se han hecho acreedoras del mencionado premio.

La consagración de voces que apelan a la ficción y autoficción está relacionada con un cambio en la construcción de la memoria y del estatuto de víctima: Nora Stejilevich con su novela Una sola muerte numerosa, Finalista Premio Planeta 1997; Marcela Solá con El silencio de Kind, Finalista Premio Planeta 1999; Patricia Sagastizábal con Un secreto para Julia, Premio La Nación 1999; Elsa Osorio con A veinte años Luz, finalista Premio Femina y Cristina Feijoó con Memoria del Río inmóvil, Premio Clarín de Novela en 2001. En efecto, Leonor Arfuch en Memoria y autobiografía (2008), explica que luego de un momento en que «Testimonio y autobiografía se entrelazaban (...) la temática dictatorial fue abordada desde la ficción y autoficción» (165), desde un relato que no se pretende verídico. Según Arfuch esta transformación ha marcado un cambio en el protagonismo de las víctimas y una apertura hacia otras voces.

En la última década, la tendencia a premiar autores que estuvieron en el exilio sigue decreciendo, pero se premia a aquellos que en la década anterior constituían los «recién llegados» que ya tienen sus proyectos narrativos definidos como Martín Kohan o Leopoldo Brizuela. La novedad la constituye el ingreso a la vida literaria de escritores que nacieron durante la dictadura como María Eugenia Almeida, Paola Kaufman, Cristian Rodríguez, Carlos Busqued y Betina González. Dentro de este grupo, se destaca Paula Robles, escritora perteneciente a la agrupación HIJOS, que vendría a dar visibilidad a un conjunto de narradores militantes de la agrupación, o de hijos que no necesariamente participaron de la lucha de Derechos Humanos como el no premiado Patricio Pron. En este conglomerado de jóvenes autores, hijos de militantes, no premiados pero con presencia y circulación en el campo literario argentino, se puede incluir a Félix Bruzzone, Laura Alcoba, Mariana Eva Pérez, Ernesto Semán, entre otros. La productividad de este elenco de escritores estaría relacionada no sólo con la centralidad de la problemática de los derechos humanos en el campo cultural durante el kirchnerismo sino también con un «reencantamiento ideológico con la política» y una «hiperestesia emotiva» (Gerbaudo 2010:90) que se percibió a partir de 2003 tanto en jóvenes como en adultos producto de un conjunto de "acontecimientos», que generaron el retorno de las polémicas. La ley de medios, el matrimonio igualitario, la megaminería a cielo abierto, el enfrentamiento por las retenciones son algunos de los hechos que movilizaron a distintos núcleos de la población (Gerbaudo 2012).

Cuando se analiza el listado de autores premiados, emergen casos de multipremiación como Fernando López, Mempo Giardinelli y Cristina Feijoó. Algunos en el mismo período, otros en períodos diferentes de autores con diferentes novelas sobre la problemática dictatorial. Reunidos en 
un cuadro, organizado por orden alfabético, los casos de autores doble y triplemente laureados en relación con la problemática de este trabajo son:

\begin{tabular}{|c|c|}
\hline AUTOR/A & NOVELA \\
\hline Andruetto, María Teresa & $\begin{array}{l}\text { La mujer en cuestión } \\
\text { Lengua Madre }\end{array}$ \\
\hline Feijóo, Cristina & $\begin{array}{l}\text { Memorias del río inmóvil } \\
\text { La casa operativa } \\
\text { Afuera }\end{array}$ \\
\hline Franz, Carlos & $\begin{array}{l}\text { El lugar donde estuvo el paraíso } \\
\text { El desierto }\end{array}$ \\
\hline Giardinelli, Mempo & $\begin{array}{l}\text { Luna Caliente } \\
\text { El santo oficio de la memoria }\end{array}$ \\
\hline Kohan, Martín & $\begin{array}{l}\text { Ciencias Morales } \\
\text { Dos veces Junio }\end{array}$ \\
\hline López, Fernando & $\begin{array}{l}\text { El mejor enemigo } \\
\text { Arde aún sobre los años } \\
\text { La odisea del cangrejo }\end{array}$ \\
\hline Martini, Juan Carlos & $\begin{array}{l}\text { El fantasma imperfecto } \\
\text { La construcción del héroe. } \\
\text { El enigma de la realidad }\end{array}$ \\
\hline Rivera, Andrés & $\begin{array}{l}\text { En esta dulce tierra } \\
\text { La revolución es un sueño eterno } \\
\text { El verdugo en el umbral }\end{array}$ \\
\hline Saccomanno, Guillermo & $\begin{array}{l}\text { El buen dolor } \\
77 \\
\text { El oficinista }\end{array}$ \\
\hline
\end{tabular}

\section{PREMIOS}

Primer Premio Fondo Nacional de las artes

Finalista

Premio ClarínFinalista Premio Rómulo Gallegos

Premio Clarín de Novela
Finalista Premio Planeta.
Primer Certamen Internacional de la Editorial
Punto y aparte

Primer Finalista Premio Planeta.

Premio La Nación/Sudamericana de Novela

Premio Nacional de Novela México.

Premio Rómulo Gallegos

Premio Herralde de Novela

Finalista Premio de Literatura Internacional, Casa de la Cultura de Berlín

Premio Latinoamericano de Narrativa Univer-
sidad de Colima, México
Premio Casa de las Américas
Finalista Premio Planeta

\section{Beca Gugenheim}

Premio Municipalidad de Buenos Aires

Boris Vian

\section{Segundo Premio Municipal \\ Premio Nacional de Novela}

Premio Club de los XIII

Premio Nacional de Novela

Premio Dashiel Hammet

Premio Seix Barral

\section{AÑo \\ 2003 \\ 2007 \\ 2011 \\ 2001 \\ 2007 \\ 2008}

1996

2004-2005

1983

1993

2007

2009

1984

1985

2005

1986

1989

1991

1985

1992

1995

2000

2009

2010

El cuadro brinda informaciones que superan la simple enumeración si se tienen en cuenta diferentes variables como la relación con las características del premio y la autonomía del campo literario. Se trata de criterios comerciales de los cuales se pueden analizar los efectos de uno u otro modo de consagración como la tensión consagración/promoción analizada en el apartado anterior. Así, se evidencia que hay autores cuyo proyecto de escritura sobre la dictadura ha merecido un reconocimiento donde predominan criterios modernos: se premia a una obra o a una trayectoria y la circulación nacional. En este sentido mencionamos a María Teresa Andruetto y Andrés Rivera. Este último ha sido consagrado tardíamente: recibió el Premio Nacional de Literatura por su trayectoria narrativa en general y en particular, por La revolución es un sueño eterno (1987) considerada una de las novelas más importantes de la década. Este reconocimiento implicó una 
consagración institucional para un escritor que desde 1972, con el libro de relatos Ajuste de cuentas, pero de manera más decisiva desde 1982 con la publicación de Nada que perder y En esta dulce tierra, Segundo Premio Municipal 1985, construyó una poética que articuló literatura y política a través de la reunión de dos elementos o propuestas estéticas: el realismo social y la aspiración experimental dada por modelos como Proust, Joyce, Kafka y Beckett. El reconocimiento tardío vino de la mano de una trayectoria en la que se pueden reconocer dos momentos de escritura: el primer momento, llamado por Rivera «prehistoria literaria», época a la que pertenecen novelas como El precio (1957), Los que no mueren (1959); y el segundo momento, denominado su «historia», que se extendería hasta el presente e incluye novelas como Nada que perder (1982), En esta dulce tierra (1984), Apuestas (1986), La revolución es un sueño eterno (1987), Los vencedores no dudan (1989), El amigo de Baudelaire (1991), La sierva (1993), El verdugo en el umbral (1994), El farmer (1997), El profundo sur (1999) y los libros de cuentos Una lectura de la historia (1982), Mitleeuropa (1993) y La lenta velocidad del coraje (1998).

Si en el párrafo anterior se analizó el caso de un autor consagrado por instituciones que mantienen criterios relacionados con la autonomía del campo literario para su selección, existe el caso opuesto de una escritora multipremiada por instancias transnacionales. Se puede observar que Cristina Feijoó ha recibido distinciones ligadas a empresas editoras y multimediales, lo cual ha generado un efecto de paradójica invisibilidad que ha llevado a la prensa a caracterizarla como «la escritora perdida». Valorada por la crítica como una sólida constructora de novelas, la sombra de la invisibilidad rodea a esta escritora en la escena literaria local. Si los sucesivos galardones obtenidos por Rivera culminaron en la consagración de un proyecto narrativo fundando una concepción de novela histórica donde se combinan experimentación e inquietud social, en el caso de Cristina Feijoó se puso en tensión premiación y consagración según lo planteado por Ducas (2013), especialmente cuando se obtienen galardones muy cercanos a las derivas del mercado editorial. La autora ha desplegado un proyecto creador que tiene como eje la problemática de la militancia y el exilio. En Memorias del río inmóvil, Premio Clarín de Novela 2001, tematiza las líneas de continuidad entre el presente democrático y el pasado dictatorial, aborda diferentes aspectos sobre la militancia y plantea interrogantes sobre el destino de los sobrevivientes; en La casa operativa, Primera Mención Premio Planeta 2007, cuenta el relato de un hijo, Manuel, que evoca una experiencia personal en relación con el pasado guerrillero de su madre; en Afuera, Primer Certamen Internacional de la Editorial Punto y Aparte 2008, aborda la problemática del exilio a través de nueve relatos que se enhebran en una misma ciudad: Estocolmo, lugar del exilio de la propia Feijoó. En un artículo aparecido en Página 12 (Berlanga 2005:s/p), la escritora revisa sus libros y su pasión por la escritura como un ejercicio complejo de autoconocimiento. En un intento de explicar la escasa repercusión de su novelística, realiza un autoanálisis en el que considera que el no frecuentar grupos de escritores, el no provenir de la academia ni de la crítica literaria, el haber comenzado a escribir después de su regreso del exilio, cuando tenía más de 40 años, hace que sea una «especie de escritora pérdida». A estos factores agrega, en su autoanálisis, el desconocimiento que tiene respecto a las editoriales y sus criterios. No obstante, además de las vicisitudes editoriales, parte de su invisibilidad puede tener que ver con el hecho de ser sobreviviente y con la inaudibilidad del discurso de los que sobrevivieron en la sociedad argentina como lo ha explicado Ana Longoni en su libro Traiciones.

Si se vuelve al cuadro anterior, se puede observar que se galardonan dos novelas de un mismo autor que pertenecen a un ciclo dentro de la propia narrativa en el que se premian autores 
extranjeros y además hay premios que habilitan circulación regional y otros internacionales con diversos efectos.

Respecto la legitimación de un ciclo dentro de un proyecto narrativo determinado, aparece el caso de Juan Carlos Martini quien recibe dos galardones de corte moderno, donde predominarían criterios de valoración simbólicos, el Premio Municipalidad de la Ciudad de Buenos Aires y el Boris Vian por La construcción del héroe (1989) y por El enigma de la realidad (1991), ambas pertenecientes al ciclo de Juan Minelli, un historiador de perfil bajo y humor triste.

Si se tiene en cuenta la información respecto de la circulación que habilitan determinados premios, surgen autores multipremiados por galardones regionales y otros internacionales. Así emerge el caso de autores legitimados, fundamentalmente, por premios regionales. Fernando López y Mempo Giardinelli son ejemplos de esta consagración en el ámbito latinoamericano logrado en momentos de exilio de ambos escritores. El caso de Fernando López es particular puesto que obtuvo premios regionales en primer término y, luego, fue distinguido con el Premio Latinoamericano de Narrativa de la Universidad de Colima y con el Premio Casa de las Américas en la década del 80 para obtener posteriormente, un reconocimiento comercial. Acorde con los cambios producidos en el campo literario, López fue ganador en instancias modernas de evaluación y veinte años después fue finalista del Premio Planeta 2005, concurso organizado por una de las empresas transnacionales de la edición más poderosas. En el lado opuesto, Martín Kohan ejemplificaría el caso de autores cuyas obras alcanzan reconocimiento internacional. Este escritor fue ganador del Premio Herralde de Novela en 2007. Si se observa el cuadro con detalle, se trata de un ejemplo claro de intraconversión del capital, en este caso a través del efecto de un premio sobre la obra anterior de un autor. Luego de obtener el premio Anagrama con la novela Ciencias Morales, Martín Kohan participa en un certamen en Berlín en 2009, con una obra anterior al premio español como Dos veces junio, que había sido publicada en 2005.

Finalmente, si se observa la nacionalidad de los multipremiados, surge el caso de Carlos Franz. El escritor chileno fue finalista del Premio Planeta con su obra El lugar donde estuvo el paraíso, en la segunda década, pero recién una década más tarde se consolida su proyecto creador y su participación en el campo literario argentino, con la obtención del Premio La Nación en 2004-2005, con su novela El desierto.

Los resultados obtenidos del cuadro de autores doble y triplemente premiados como el análisis realizado de las particularidades de los distintos proyectos creativos como los de Martín Kohan, Nora Strejilevich y de Cristina Feijoó no sólo reafirman la hipótesis que sostiene que se premian novelas sobre la dictadura, sino que confirmarían que se construyen ficcionalizaciones respecto a determinados cronotopos, como veremos con más detalle más adelante.

\section{e) Premios y ventas}

Llegado a este punto donde la relación entre dictadura y premios es insoslayable, surge la pregunta inevitable por el rendimiento económico de las novelas laureadas. Este punto es difícil de responder ya que no se cuenta con cifras exactas, pero existe un modo de acercamiento a través de las listas de los más vendidos. La consulta a determinadas librerías, la diversidad de los puestos de venta y su capacidad comercial, la representatividad territorial, la disparidad de criterios utilizadas por el librero para la confección de las listas de ventas constituyen una información un tanto imprecisa de la efectividad de las ventas, aunque resultan significativas de la realidad del 
mercado, de sus tensiones, del tipo de producto que circula y de su caducidad sistemática. Esta nómina de libros y autores se sostiene en una lógica circular de que las ventas producen más ventas. Sin embargo, permiten observar el comportamiento de libros, autores y editoriales y revelan inquietudes, intereses y expectativas. La lista de éxitos «es una representación pública (más o menos fiable) de un determinado grupo de libros en cuanto producto mercantil: nos confirma que ese objeto ha circulado, que ha sido expuesto, que ha cristalizado su condición de mercancía y que ha sido comprado no necesariamente leído» (Peñate Rivero:33).

Estas listas se constituyen en plataformas de promoción de los títulos que la integran y materializan las estrategias de editoriales y autores para ocupar el mercado del libro y por lo tanto las frecuentes tensiones y luchas que lo atraviesan. Una de las listas de éxito de ventas es Boca de Urna del suplemento Radar Libros del periódico Página 12, que apareció desde enero de 2005 hasta abril de 2011. Basado en la consulta a diferentes librerías entre las que se pueden mencionar Boutique del Libro, Fedro, Antígona, Crack Up, Cúspide, Libros del Pasaje, Librería Edipo, se establece el ranking de los más vendidos en librerías que no están ligadas al circuito transnacional. Este listado distingue ficción de no ficción y tiene una periodicidad semanal, lo que da un seguimiento más ajustado del movimiento del mercado. Durante los años de existencia de Boca de Urna, se observó que desde 16 de diciembre de 2007 hasta el 30 de abril de 2011 aparecían en la nómina de ficción novelas relacionadas con la dictadura. No siempre estas ficciones ocuparon el primer lugar, pero su permanencia en el tiempo daría cuenta de su posibilidad de circulación y sobre todo de ventas.

La novela que más tiempo estuvo liderando el ranking fue Blanco nocturno de Ricardo Piglia que durante diez semanas en forma intermitente, presidió la lista. Por su parte, tres presidieron el listado durante dos semanas. Una fue El oficinista de Guillermo Saccomanno, la segunda fue Cuentas pendientes de Martín Kohan y la tercera fue Historia del llanto de Alan Pauls. Otras novelas que aparecen en las listas durante el período 2007-2011, pero ocupando desde segundos a quintos puestos son: Ciencias morales de Martín Kohan; El lugar perdido de Norma Huidobro; A quien corresponda de Martín Caparrós, En otro orden de cosas de Rodolfo Fogwill; Purgatorio de Tomás Eloy Martínez; Demasiado héroes de Laura Restrepo; La pregunta de sus ojos de Eduardo Sacheri; Un yuppie en la columna del Che de Carlos Gamerro.

Por un lado, el análisis todavía provisorio de estas listas evidencia que durante varios años las novelas que abordaron la problemática dictatorial vendieron en forma constante aun cuando no fueron auténticos best sellers. Y por otro lado, desde la perspectiva de los premios, emerge el efecto que estos ejercen sobre las ventas, ya que como se mostró, varias novelas laureadas ocuparon durante un período considerable, los primeros lugares de ranking entre los libros más vendidos. Así, esta relación entre premios y ventas, consolida la hipótesis, desde un punto de vista de la economía de los bienes literarios, de que los mecanismos de premiación consagraron novelas sobre la dictadura.

\section{f) Novelas y cronotopos}

Si se observa nuevamente el cuadro de novelas multipremiadas, emerge una preferencia por galardonar recurrentemente novelas que organizan su tiempo-espacio en relación con el cronotopo de pruebas y aventuras. ${ }^{13}$ De un total de 71 novelas premiadas 56 se organizan en torno al tiempo de la aventura: novelas policiales, thrillers, relatos de iniciación o Bildungsroman, constituyen el entramado del tiempo de la prueba que se visualiza en el siguiente cuadro comparativo: 
Cantidad de novelas premiadas con cronoto-

po de aventura y prueba

Premiadas

Cronotopo aventura

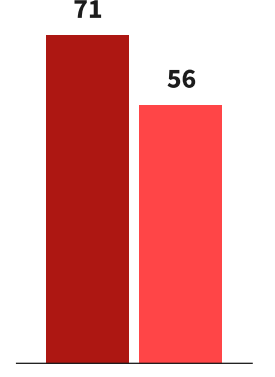

Ahora bien, si se tienen en cuenta los tres períodos, en el primero se galardonaron 14 novelas, en el segundo 19 con el cronotopo de prueba y aventura y en el tercero 23. Volcados en porcentajes se obtiene:

Novelas premiadas con cronotopo de aventuras por decenio

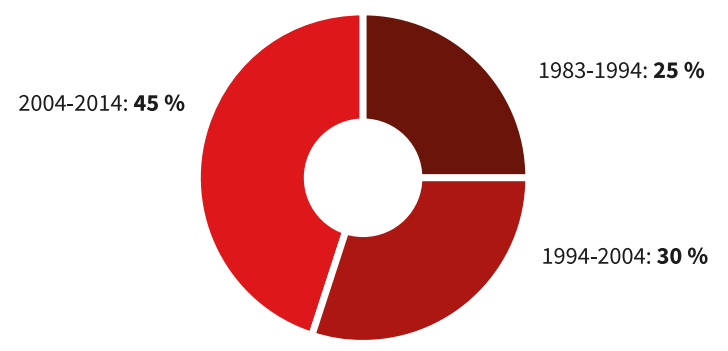

El cuadro permite observar que en el último período donde predominan instancias comerciales de premiación es mayor el porcentaje de novelas premiadas con el cronotopo de novelas de pruebas y aventuras. También se puede visualizar un crescendo continuo si se tienen en cuenta los porcentajes de los dos primeros períodos: $25 \%$ y $30 \%$. De manera que se puede afirmar que a medida que se produce el desarrollo de la transnacionalización de la edición se consagra cada vez con más frecuencia el cronotopo de pruebas y aventuras. Y dentro de este modo de organización del espacio y el tiempo del relato, es el cronotopo genérico del policial ${ }^{14} \mathrm{y}$ sus variantes junto al cronotopo de la imposibilidad de idilio los que se han distinguido preferentemente.

\section{Conclusiones}

La legitimación recurrente por parte de los premios literarios de estos cronotopos habilita la construcción de un ficcionalización de la lucha armada, la militancia y la dictadura centrada fundamentalmente en torno a la violencia y sus efectos represivos, lo cual empobrecería la conciencia social sobre la comprensión del pasado en cuanto a sus secuelas y consecuencias en el presente, ya que obturan otras evaluaciones de lo ocurrido por parte de los diferentes actores. Este interés de los conglomerados editoriales por legitimar novelas que abordan la problemática dictatorial vehiculiza la participación nacional en un consenso internacional caracterizado por preocupaciones memorialísticas, especialmente vinculadas con el Holocausto, pero también, esta ampliación del campo de circulación produce la posibilidad de generar ganancias con los textos, muchos de los cuales estuvieron entre las listas de los más vendidos.

Por otra parte, esta cronotopía dominante, legitimada desde los premios literarios, se caracteriza por propiciar el «hipérbaton histórico», es decir, una «inversión», una «permuta» del tiempo histórico que se define a costa del futuro, el cual se vacía, se rarifica o se «desangra». Precisamente, las 
novelas premiadas sobre la lucha armada, la militancia y la dictadura favorecerían esta inversión temporal que llevaría la creencia y la confianza en un tiempo futuro igualitario al pretérito, proceso por el cual toda idea de cambio, de revolución, queda bloqueada, anacronizada, caducada en el pasado, imposible de ser pensada críticamente. Sin embargo, la concepción bajtiniana (Bajtín 1989) sostiene que los elementos semióticos en una cultura como los géneros discursivos y las representaciones son «arcaísmos vivos» que propician una noción de temporalidad e historicidad dinámica, fluyente e inconclusa, ajena a toda idea simplista de movimiento rectilíneo hacia delante. Los sentidos nunca son aniquilados, muertos, porque no hay sentido en sí mismo sino que este es una construcción dinámica permanente del sujeto hablante en la interacción discursiva que produce que los sentidos pasados sean pasibles de ser recordados en cualquier momento del desarrollo ulterior y en un contexto renovado con un aspecto nuevo. Por ello, no es imposible imaginar que los sentidos obturados por un vector de la literatura argentina, el de las novelas premiadas, en torno a la militancia, la dictadura y la lucha armada, puedan tener en otra circunstancia contextual y con sentidos renovados, su «fiesta de resurrección» (393).

\section{Notas}

1 Como en el caso de la novela de Carmen Ortiz, El resto no es silencio, que fue seleccionada para la Promoción de la literatura de Asia, África y América Latina De Frankfurt para su traducción al alemán (1990) o A veinte años Luz, Premio Amnesty Internacional 1999, o de la Mención del Premio Clarín 1999 de la novela Kelper, de Raúl Vieytes.

2 Inicialmente se constituyeron modos narrativos de visibilización, denuncia y juzgamiento de la represión, donde predominó la información periodística, el testimonio de sobrevivientes y familiares y la judicialización de la historia vía tribunales y condena a los máximos mandos de las Fuerzas Armadas. Una segunda etapa que sucede en los 90 mostró el surgimiento de emprendimientos biográficos, autobiográficos, documentarios y periodísticos tanto escrito como fílmico que hicieron progresivamente presente una narrativa politizadora. En el presente, afirma Casullo, se asiste a una etapa signada por propuestas documentales y ficcionales donde se cruzan distintas vivencias de relatos generacionales y de Hijos de desaparecidos en disputa de versiones, a la vez que se abrió una discusión ya no sólo sobre lo acontecido, sino sobre lo que se puede denominar la historia de las narraciones de la memoria de los 70. En este contexto se percibe la polémica entre una voz narrativa testimonial que crece desde distintas escrituras y estéticas, la tarea ensayística que busca asentar una mirada teórica sobre operatorias discursivas, y algunos trabajos historiográficos que procuran enunciaciones documentadas sobre aquella época. Esta etapa expresa la tensión de la memoria por sus narrativas, narradores y sus teoréticas de las narratividades.

3 Para el Profesor Gómez, el Diario La Nación y la SADE fueron instituciones culturales que apoyaron al régimen. Con resentimiento, el Profesor Gómez critica también los mecanismos de selección y el rito de premiación de la mencionada institución. A juicio del profesor, cualquier «esclerótico habitué del haikú se merecía la faja» (Saccomannoo:71-72).

4 La investigadora Alejandra Laera (2014) explica que partir de un artículo en la revista Vigencia de 1981, Fogwill critica el aspecto económico de los premios. Los resultados de los concursos son conceptualizados por Fogwill como una «mera lotería» o como "un sistema de censura invertido», por el cual los escritores que participan en dichos certámenes deben adaptar el estilo, la frase, el contenido, la forma a los requisitos de las publicaciones o de quienes auspician el concurso (266-267).

5 En la novela se hace mención a los galardones literarios en dos oportunidades. En la primera deja entrever aspectos de la premiación desde la perspectiva de escritores amateurs, como los deseos de consagración pero también la fugacidad del mismo: «repartíamos y repartíamos las invitaciones, como esas mujeres que ganan premios en un concurso y quisieran que se cierre la canilla detrás de ellas» (Krimer:108). Mientras que en la segunda oportunidad, el premio aparece compensando las pérdidas, la vida en el extranjero, y la imposibilidad de regresar al propio país luego de la muerte de su esposo. El cuento 
«La oscura noche» inspirado en la historia del cura Benítez, un sacerdote que asesina a su mujer e hija y que había sido duramente criticado en la peluquería del pueblo por las mujeres de la cementera, gana el Segundo Premio de Narrativa Ciudad de Huelva (196).

6 En realidad el aspecto económico no desaparece totalmente, dado que Julieta se decide a estudiar a esta escritora porque conseguiría el apoyo económico para su proyecto.

7 La composición, el prestigio y la unanimidad son aspectos que hacen a la reputación de un premio. Como explica Englihs, es una relación circular: cuanto más prestigioso es el jurado más prestigio tiene un premio.

8 En una economía del prestigio, como la describe English, caracterizada por el incremento de la importancia de un sistema de credencialidad y consagración que ha monopolizado la producción y distribución del capital simbólico, se ha generado la necesidad de controlar este capital para el ejercicio del poder. En este sentido los premios son una maquinaria administrativa compleja para lograr tal fin y administrar socialmente la reputación. En este dispositivo no sólo participa el escritor sino también muchos otros agentes, intermediarios, cuyo específico interés no coincide ni con artistas ni con editores. Existiría también una «aparente circularidad» de acuerdo o dependencia de los jueces en relación con el aparato administrativo que se hace evidente en los escándalos. Los escándalos no sólo dejan al descubierto la escisión o la tensión sobre la que se funda la relación circular entre maquinaria administrativa orientada a producir un ganador y la responsabilidad del escritor como jurado, sino que confirma la tesis de English que los escándalos más comunes en torno a los premios tienen que ver con quienes tienen la función de elegir.

$9 \mathrm{El}$ mercado actualmente no es simplemente una ideología dominante sino un proceso cultural y social hegemónico, por lo tanto es una dimensión dinámica, contradictoria, que conlleva procesos de asimilación y de diferenciación, de dominación y resistencia, de control y fuga en su propio interior. Según Raymond Williams en Cultura, sociología de la comunicación y del arte (1981), la producción para el mercado implica la concepción de la obra de arte como mercancía y la del artista como una clase particular de productor de mercancía aun cuando las relaciones sociales de los artistas implicados total o parcialmente en la producción de la misma son variables. En una etapa de producción posartesanal, Williams considera que si bien el mercado ha jugado un papel liberador en relación con las antiguas formas centralizadas de dominación cultural, ha generado dos nuevos tipos de control. Uno que se produce cuando la obra se ha convertido en mercancía producida para ser vendida con un beneficio, motivo por el cual, las obras que producen pérdidas son abandonadas, mientras que las que proporcionan ganancias experimentan una expansión. El segundo modo de control lo constituyen las operaciones planificadas de marketing en las que determinados tipos de obras son promocionadas mientras que otras son abandonadas a su suerte. Pero, una vez que se han generalizado las condiciones de mercado, precisa Williams, los productores con frecuencia interiorizan las relaciones conocidas o posibles del mercado. Esto representa un proceso complejo que abarca desde la producción obvia para el mercado, la cual suele justificarse como la obra que el productor «siempre ha querido realizar» y las intenciones del producto, hasta aquellos casos en que se aceptan las determinaciones prácticas del mercado pero la obra original, es, con todo, sustancialmente realizada. Muchos escritores y artistas, en medio de la vigencia de los paradigmas absolutos, circulan y subsisten críticamente por la capacidad de practicar la ambivalencia frente a las exigencias hegemónicas. Por otra parte, el mercado inquieto y creador por sus innegables innovaciones, es, por naturaleza, profundamente reproductor de las demandas conocidas, sintetizadas en la frase «el gusto del público». Generalmente, dice Williams, la compatibilidad de la obra con los medios y determinantes técnicos, económicos y sociales implica simetría con el orden social con el cual opera y, el «tipo de producto no integrado en el mercado» o la obra "subvencionada», es, con frecuencia, un aspecto de esta simetría, en el sentido de que por medio de la selección de algunos tipos de obras, se permite la extensión parcial del mercado y la protección de este frente a otros tipos de desafíos social y cultural.

10 Sustentada en la crítica convencional sobre los premios que reza que «están todos arreglados», Kusminsky muestra la degeneración del trabajo creador del artista por influencia del dinero y las presiones del mercado sobre un proyecto narrativo. Marcos comprende que para hacerse un nombre en el ámbito literario debe ceder, adaptarse y cambiar. Así, aunque pertenecía a un grupo de escritores que consideraban que se podía vivir de la literatura sin caer en el espacio «degradado del mercado editorial masivo» deja de lado este posicionamiento «pueril o acaso inocente, para las reglas salvajes del mercado» (Kusminsky:60). 
Por ello, acepta el Premio que su agente literario español le consigue y se somete a las reglas que determinan el trabajo creativo provenientes de un campo literario regido por la lógica mercantil. Así, se construye como un personaje de la literatura y muestra el modo de producción de un escritor, es decir la manera como se arma el mito o se instala en el imaginario colectivo, un proyecto creativo. A partir de la aceptación del galardón, Marcos introduce al lector en los pasos que se deben seguir para pensar una novela premiable, como presentar en tiempo y forma el manuscrito, respetar la extensión requerida en forma exacta, y la elección de un género y un tema que formen parte del catálogo de motivos literarios.

11 En el primer período, tienen mayor presencia los premios otorgados por la crítica y los escritores a obras ya publicadas, como podemos ver en el caso del Premio Boris Vian y el del Club de los XIII. El primero fue creado durante la dictadura para premiar, acaso con un nombre indiscernible por la censura —el del poeta francés-, la obra que significaría un corte, un texto original y diferente. En estos certámenes el escritor no se presenta a un concurso sino que el libro premiado ya está publicado y es conocido por los lectores, de manera que la decisión del jurado no afecta la publicación ni la circulación de la obra: «El libro vale por sí mismo, no hay intereses en juego para su publicación ni influye tanto el azar» (Sifrim:s/p). El Premio Boris Vian nació, como ya se dijo anteriormente, en plena dictadura militar como una propuesta contraria a los premios oficiales. Se definió como «antipremio» y basó los presupuestos de un relevamiento escritural en litigio con las marcas y puntuaciones convencionales. Su inscripción promovió una genealogía que en los sucesivos textos señalan y legitiman su propia historia. En sus inicios, no se trataba de un certamen sino que varios escritores se ponían de acuerdo sobre el señalamiento de un texto. No había estatutos ni reglamentos, pero sí cierto orden que hilvanaba a los premiados a ser jurados y a los jurados a permanecer como lectores. Otro rasgo que lo caracterizaba es otorgar una obra de arte como distinción. Así, En el corazón de junio de Luis Gusmán en 1983 y El río de las congojas de Libertad Demitrópulos, recibido un año después de su reedición, en 1997, obtuvieron esta distinción de los pares como: Juan Jacobo Bajarlía, Eduardo Grüner, Liliana Heer, Nicolás Rosa, Leónidas Lamborghini, Héctor Libertella, Hugo Padeletti y Laura Klein, entre otros. En el año 2002 el Premio Boris Vian se incorporó a la SEA. El último jurado del Boris Vian, compuesto por Leónidas Lamborghini, Tununa Mercado, Tomás
Eloy Martínez, Noé Jitrik, Hugo Padeletti, Juan Jacobo Bajarlía, Héctor Libertella, Carlos Arcidiácono, Laura Klein, Roberto Raschella y Liliana Heer, consideró oportuno que el premio tuviera, por primera vez en su trayectoria, un referente institucional, en razón de que existiría coincidencia en un mismo espíritu entre el Premio Boris Vian y los objetivos de la Sociedad de Escritoras y Escritores de la Argentina. Por su parte, el Premio Sigfrido Radaelli otorgado por el Club de los Trece, fue para El verdugo en el umbral de Andrés Rivera, en 1995. Este premio se da a la mejor novela del año, consiste en una cena y una obra de arte y la otorgan trece escritores y críticos argentinos como un reconocimiento de los colegas. Además de los premios mencionados, ambos de gravitación local, se debe tener en cuenta el premio Dashiell Hammett, instituido en 1987 y auspiciado por la Asociación Internacional de Escritores Policíacos. Destinado a distinguir la mejor novela policial escrita en español, se entrega anualmente en la Semana Negra de Gijón. No tiene premio en dinero sino que es una distinción otorgada por los pares.

Un caso especial, es el Premio Pablo Poblet que coronó en 1989 una novela que había sido publicada en el exilio en 1984: El frutero de los ojos radiantes de Nicolás Casullo. Este galardón fue entregado por la librería Clásica y Moderna con características de los certámenes de pares y oficial. El jurado estuvo integrado por Beatriz Sarlo, Enrique Pezzoni y Héctor Tizón y fue apoyado por Mario O’Donnell desde la Secretaría de Cultura. Este premio originado en los albores democráticos duró dos años: 1985-1986.

Recibieron la consagración por parte de pares las siguientes novelas: En el corzón de Junio, de Luis Gusmán, Sombras nada más, de Antonio Di Benedetto, El río de las congojas, Soledad Demitrópulos, recibieron el premio Boris Vian; mientras que 77, Guillermo Saccomanno, y Blanco Nocturno, Ricardo Piglia, fueron ganadoras del premio Dashiel Hammet.

12 Varias son las razones de la existencia de los casos doble y triple premiación. La proliferación de premios ha significado que más artistas, autores y trabajos puedan llegar a alcanzar la distinción de un premio. Pero esta compensación, aparentemente democrática, es negada por un tendencia que lleva a que los premios se acumulen en manos de «big winners» (English:334). Este fenómeno se relacionaría con la «intraconversión de capital», categoría que apoyada en la concepción bourdesiana de la naturaleza doble de todo producto cultural, que permite analizar la posibilidad de conversión del capital simbólico acumulado en dinero. Los premios constituyen un 
instrumento para realizar transacciones o negociaciones entre lo cultural o literario y lo económico. En la crítica literaria española, Julio Peñate Rivero ha acuñado el concepto de efecto de arrastre para explicar aspectos de la concentración de distinciones en una obra o autor.

$13 \mathrm{El}$ cronotopo de pruebas y aventuras se compone por una serie de segmentos cortos dentro de los cuales se presentan las distintas pruebas Dentro de este cronotopo se pueden incluir, en- tre otras, López Fernando, El mejor enemigo y La odisea del cangrejo; Martínez, Dámaso, El informante; Piglia, Ricardo, Blanco Nocturno; Argemí, Raúl, Penúltimo nombre de guerra; Mallo, Ernesto, La aguja en el pajar; Argemí, Raúl, Penúltimo nombre de guerra.

14 Dentro de este cronotopo se pueden incluir, entre muchas otras: Giardinelli, Mempo, El santo oficio de la memoria; Strejilevich, Nora, Una sola muerte numerosa; Andruetto, María Teresa, Lengua Madre; Neumann, Andrés, Una vez argentina.

\section{Bibliografía}

AA. VV. (2003, 26 de febrero). «Una novela sobre la dictadura gana el Premio Emecé». Diario C. Web. (2004). Entrevista a Martín Kohan (por Martín Abadía): «La literatura hoy en día está acuartelada». La periódica revisión dominical, 26 de febrero de 2004. Web.

(2011). «Relanzamientos de los premios nacionales». Diario Registrado. Web. (2012). «Galardones que nunca llegan». Página 12. Web.

Abad Faciolince, Héctor (2014). «Razón y sinrazón de las justas literarias». El malpensante. Web.

Acín, Ramón (1990). Narrativa o consumo literario (1975-1987). Zaragoza: Prensa Universitaria. (2000). La línea que come de tu mano: aproximación al simulacro. Madrid: Ediciones de la Torre. Aguirre, Osvaldo (2012a). «Los premios literarios en Argentina». Bazar Americano. Web. (2012b). «Los segundos son buenos». La Capital. Web.

Arfuch, Leonor (2007). El espacio biográfico. Dilemas de la subjetividad contemporánea. Buenos Aires: Fondo de Cultura Económica.

- (2008). Crítica cultural entre política y poética. Buenos Aires: Fondo de Cultura Económica. (2013). Memoria y autobiografía. Exploraciones en los límites. Buenos Aires: Fondo de Cultura Económica. Bajtín, Mijail (1982). Estética de la creación verbal. México: Siglo XXI. Traducción de Tatiana Bubnova. (1989). «Las formas del tiempo y del cronotopo en la novela. Ensayo de poética histórica». Teoría y estética de la novela. Madrid: Taurus. Traducción de Helena S. Kriukova y Vicente Kazkarra. Balaguer, Miguel (2014). «De editores y premios literarios». La Balandra (otra narrativa). Web. Bencomo, Anadeli (2006). «La lógica de los premios literarios: política cultural, prestigios literarios y disciplinas de lectura en la época de la literatura transnacional». Estudios, 13-29. Web. Berlanga, Ángel (2005). «El oscuro nombre de la bestia». Página 12. Web.

Bourdieu, Pierre (1966). Campo del poder y campo intelectual. Buenos Aires: Montressor.

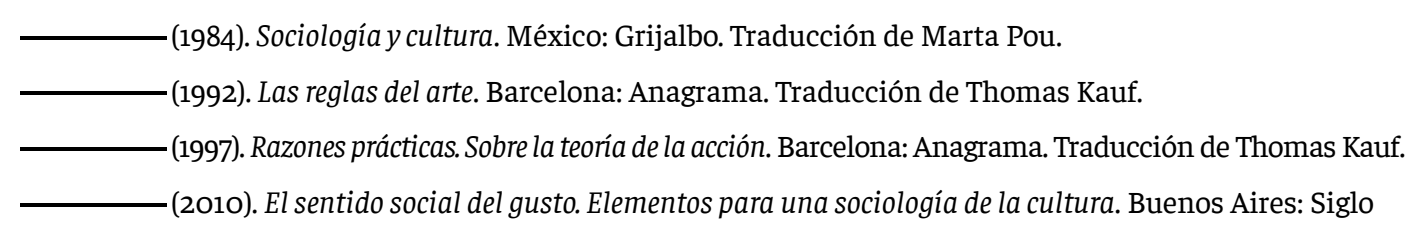
XXI. Traducción de Alicia Gutiérrez.

Bracamonte, Jorge (2007). Los códigos de la transgresión. Lengua literaria, lengua política y escritura contemporánea en la narrativa argentina. Córdoba: Universidad Nacional de Córdoba.

Brizuela, Leopoldo (2012). «Los concursos tienen un poder simbólico». Bazar Americano. Web.

Brown, Megan (1994). The receptions of Spanish American fiction in West Germany 1981-1991. A study of best sellers. Tübingen: Niemeyer Verlag. 
Calveiro, Pilar (1998). Podery desaparición: los campos de concentración en Argentina. Buenos Aires: Colihue. Casanova, Pascale (2001). La república mundial de las letras. Barcelona: Anagrama. Traducción de Jaime Zulaika.

Casullo, Nicolás (2007). Las cuestiones. Buenos Aires. Fondo de Cultura Económica.

Catelli, Nora (2010). «Circuitos de consagración en castellano: mercado y valor». Boletín del Centro de Estudios de Teoría y Crítica Literaria, 15. Web.

Cesarotto, Oscar (1985). «Cultura vs economía». Cultura y Nación, 5-6.

De Diego, José Luis (2001). ¿Quién de nosotros escribirá el Facundo? Intelectuales y escritores en Argentina (19701986). La Plata: Al Margen.

- (2007). Las novelas de Juan Martini: una poética del error. La Plata: Al Margen.

Drucaroff, Elsa (2000). La narración gana la partida. Buenos Aires: Emecé.

-(2011). Los prisioneros de la torre. Política, relatos y jóvenes en la postdictadura. Buenos Aires: Emecé. (2014). «La transparencia en los premios literarios». La Balandra (otra narrativa). Web.

Ducas, Sylvie (2010). «L'auteur? Soyons modeste: Le cygne a terre. Auctoirté auctorialle et prix littéraires», en Emmanuel Boujú, director. La autorité en littérature. Rennes: Presses universitaire de Rennes, 277-287. (2011). «Entretiens autor d'un prix: Auteur cherche ecrivain», en Audrey Alves y Michel Pourchet. Le médiations de l'écrivain. Les conditions de la création littéraire. París: L'Harmattan, 237-270. (2013). La littèrature à quel (s) prix? Histoire des prix littèraires. París: La Dècouverte.

English, James (2005). The economy of Prestige: Prizes, awards and the circulation of culture value. Harvard: Harvard University Press.

Fagnani, Fernando (2014). «De editores y premios literarios». La Balandra (otra narrativa). Web.

Fogwill, Rodolfo (2008). «La herencia cultural del proceso». Los libros de la guerra. Buenos Aires: Mansalva, 64-72.

Gallego Cuiñas, Ana (Ed.) (2012). Entre Argentina y España. El espacio trasatlántico de la narrativa actual. Madrid: Iberoamericana/Vervuert.

Gamerro, Carlos (2006). «Para una reformulación del género policial argentino». El nacimiento de la literatura argentina y otros ensayos. Buenos Aires: Norma, 46-53.

Gerbaudo, Analía (2011). «La literatura en la Universidad Argentina (1984-1986). Intervenciones desde una política de la exhumación». Moderna Sprac. Web.

(2012). «Sobre la dicha de tener polémicas». Estudios de Teoría Literaria. Revista Digital. Artes, letras y humanidades. Mar del Plata: Universidad Nacional de Mar del Plata, 83-98. Web.

Giardinelli, Mempo (2009). El santo oficio de la memoria. Buenos Aires: Edhasa.

(2013). El género negro. Orígenes y evolución de la literatura policial y su influencia en Latinoamérica. Buenos Aires: Capital Intelectual.

Gilman, Claudia (2003). Entre la pluma y el fusil. Debates y dilemas del escritor revolucionario en América Latina. Buenos Aires: Siglo XXI.

Giordano, Alberto (2008). El giro autobiográfico en la literatura argentina actual. Buenos Aires: Mansalva. Gramuglio, María Teresa (2002). «Políticas del decir y formas de la ficción. Novelas de la dictadura militar».

Punto de vista, 74, 9-14.

Gregorich, Luis (1985, 4 de abril). «Libro e identidad nacional». Cultura y Nación, 4-5.

Heinnich, Nathalie (1999). L'epreuve de la gradeur. Prix Littéraires et reconnaissance. París: La Décuverte.

Indij, Guido (2014). «De editores y premios». La Balandra (otra narrativa), 70. Web.

Jitrik, Noé (2009). Panorama histórico de la literatura argentina. Buenos Aires: El Ateneo. 
Krimer, María Inés (2009). Lo que nosotras sabíamos. Buenos Aires: Emecé.

Kumisnsky, Gustavo (2011). Entrevista (por Zunini, Patricio). «La ficción en el borde entre la mentira y la verdad». Eterna Cadencia. Web.

Laera, Alejandra (2007). «Los premios literarios: recompensa y espectáculo», en Luis Cárcamo Huechante, compilador. El valor de la cultura. Arte, Literatura y mercado en América Latina. Rosario: Beatriz Viterbo, $43-65$.

(2010). «Para una historia de la literatura argentina: orígenes, repeticiones, revanchas». Prismas. Web.

(2014). Ficciones del dinero. Argentina 1890-2001. Buenos Aires: Fondo de Cultura Económica.

Lahire, Bernard (2006). La condition littèraire. La double vie des écrivains. París: La Découverte.

Liefeld, Juan Pablo (2005). «Las chicas de letras se masturban así». El interpretador. Web.

Link, Daniel (2009). Fantasmas. Imaginación y sociedad. Buenos Aires: Eterna Cadencia.

-(Comp.) (2003). El juego de los cautos. Literatura policial: de Edgard Alan Poe a P. D. James. Buenos

Aires: La Marca.

Longoni, Ana (2007). Traiciones. Buenos Aires: Norma.

López Abiada, José Manuel (2001). Entre el ocio y el negocio: industria editorial y literatura en la España de los '9o. Madrid: Verbum.

López, María Pía (2011). «Una lengua en la contrarrevolución», en AA. VV. Fogwill. Literatura de provocación. Buenos Aires: Universidad Nacional de General Sarmiento.

Ludmer, Josefina (1999). El cuerpo del delito. Un manual. Buenos Aires: Perfil.

- (2010a). Aquí América Latina. Una especulación. Buenos Aires: Eterna Cadencia.

(2010b). «Lo que viene después». Seminario-encuentro Literatura y después. Reflexiones sobre el

futuro de la literatura después del libro. Web.

Lvovich, Daniel. y Jacqueline Bisquert (2008). La cambiante memoria de la dictadura. Discursos públicos, movimientos sociales y legitimidad democrática. Buenos Aires: Universidad Nacional de General Sarmiento/Biblioteca Nacional.

Mayer, Marcos (2014). «Los invisibles: jurados de preselección». La Balandra (otra narrativa). Web.

Molina, Cristian (2013). Relatos de mercado. Literatura y mercado editorial en el Cono Sur (1990-2008). Rosario: Fiesta Ediciones, CELA.

Ortega, Julio (Ed.) (2010). Nuevos hispanismos interdisciplinarios y transatlánticos. Madrid: Iberoamericana/ Vervuert.

Osten, Manfred (2008). La memoria robada. Los sistemas digitales y la destrucción de la cultura del recuerdo. Breve historia del olvido. Madrid: Siruela.

Pampa Arán, Olga (2009). «Las cronotopías literarias en la concepción bajtiniana. Su pertinencia en el planteo de una investigación sobre narrativa argentina contemporánea». Tópicos del seminario. Web.

Peñate Rivero, Julio (1997). «Lista de éxitos y mercado editorial en España», en José López de Abiada y otros. Entre el ocio y el negocio: industria editorial y literatura en la España de los ‘9o. Madrid: Verbum, 219-250.

Poblet, Pablo (1985, 4 de abril). «La demanda». Cultura y Nación, Clarín. Buenos Aires.

Ruiz, Laura (2005). Voces ásperas. Las narrativas argentinas de los 9o. Buenos Aires: Biblos.

Saccomanno, Guillermo (2000). 77. Buenos Aires: Planeta.

Sarlo, Beatriz (2005). Tiempo pasado. Cultura de la memoria y giro subjetivo. Una discusión. Buenos Aires: Siglo XXI. (2006). «Sujetos y tecnologías. La novela de la historia». Punto de vista, 86, 1-7.

Sarlo, Beatriz y otros (1987). Ficción y política. La narrativa argentina durante el proceso militar. Buenos Aires: Alianza. 
Schavelzon, Guillermo (2014). «Concursos literarios ¿Sirven para algo?». La Balandra (otra narrativa) 70. Web. Shcliemann, Eva (2008). Der Prix Gouncourt und andere franzosische Literaturpreise. Berlín: Verlag Dr. Müller. Sifrim, Mónica (1998). «De glorias y de olvidos». Clarín. Web.

Sorá, Gustavo (2011). «Editar la nación. Bicentenario argentino en Frankfurt», en Graciela Baticuore y

Sandra Gayol, compiladoras. Tres momentos de la cultura argentina: 1810, 1910. Buenos Aires: Prometeo. Tabarovsky, Damian (2004). Literatura de izquierda. Buenos Aires: Beatriz Viterbo.

Tadié, Jean Ives (1989). La novela de aventuras. México: Fondo de Cultura Económica.

Vezzetti, Hugo (2009). Sobre la violencia revolucionaria. Memorias y olvidos. Buenos Aires: Siglo XXI.

Williams, Raymond (1981). Cultura, sociología de la comunicación y el arte. Barcelona: Paidós.

(1988). Marxismo y literatura. Buenos Aires: Península. Traducción de Pablo di Masso.

(1994). Sociología de la cultura. Barcelona: Paidós. Traducción de Graziela Baravalle. (2000). Palabras Clave. Buenos Aires: Nueva Visión. Traducción de Horacio Pons.

Witt, Nicole (2001). «Premios literarios entre cultura, negocios y política», en José Manuel López Abiada.

Entre el ocio y el negocio: industria editorial y literatura en la España de los '9o. Madrid: Verbum, 305-318. 